\title{
Can Green Car Taxes Restore Efficiency? Evidence from the Japanese New Car Market*
}

\author{
Yoshifumi Konishi $^{\dagger}$ \\ Faculty of Liberal Arts \\ Sophia University
}

and

Meng Zhao

Department of Economics

The University of Tokyo

Draft: January 11, 2015

${ }^{*}$ We thank seminar participants at Kobe University, Sophia University, Waseda University, and the Fifth World Congress of Environmental and Resource Economists. The study was in part supported by the financial support from Japan Society for the Promotion of Science (JSPS), Grant-in-aid for Young Scientists (Grant number: 25780171). We also thank Yukiko Omata for her excellent research assistance in the data collection.

†Corresponding author: y-konishi@sophia.ac.jp. 
Abstract: We quantify the impacts of Japan's green vehicle taxation policy since 2009. A random-coefficients logit model is estimated for quarterly automobile sales data between 2007 and 2012 from the Japanese new car market. We construct the location of product-specific taxes in the characteristics space as instruments to control for endogeneity of car prices. The policy-induced large variation in effective car prices are then used to obtain consistent estimates of own- and cross-price elasticities. Our results indicate the significantly positive effects of the policy on both the average fuel efficiency and the total sales of new vehicles. Consequently, the policy induced only a small reduction in vehicle $\mathrm{CO}_{2}$ emissions, yet a sizable increase in economic surplus, relative to the no-policy counterfactual.

Key Words: Random-coefficients logit, discrete choice models, product differentiation, automobile demand, carbon emissions, fiscal instruments 


\section{Introduction}

Emissions from motor vehicles continue to present a daunting challenge to policy practitioners. An efficient emissions tax would be infeasible, either economically because measurement of such emissions would be inaccurate and expensive (Fullerton and West, 2002; Fullerton and Gan, 2005), or politically because monitoring of such emissions would likely intrude drivers' privacy. In theory, however, the regulatory authority could combine car and gasoline taxes to induce optimal vehicle consumption both at the extensive margin (i.e., car ownership) and the intensive margin (i.e., car utilization), correctly accounting for the negative externality cost of vehicle emissions (Fullerton and West, 2002; Innes, 1996). ${ }^{1}$ Taken in this view, several developed countries have recently gone through green reforms on vehicle taxation. Examples include France's subsidy program, Germany's car tax reform, Japan's ecocar subsidy program, Sweden's green car rebate program, and U.S. accelerated vehicle retirement program.

Optimal coordination of the two fiscal instruments is, however, complicated for a number of reasons. First, emissions from motor vehicles include not only carbon dioxides $\left(\mathrm{CO}_{2}\right)$, which depend only on fuel consumption, but also carbon monoxide $(\mathrm{CO})$, nitrogen oxides $\left(\mathrm{NO}_{x}\right)$, and reactive hydrocarbons $(\mathrm{HC})$, whose emissions per unit of fuel consumption may vary substantially due to vehicle characteristics. In theory, optimal vehicle taxation must reflect the negative externality costs associated with vehicle choice that are not internalized by optimal fuel taxation. Because consumers choose car characteristics by partly internalizing the negative external cost of fuel consumption, the optimal amount of vehicle tax may be lower in the presence of fuel taxation than the negative externality costs of their vehicle choice in the absence of fuel taxation (Fullerton and West, 2002). ${ }^{2}$

Second, automobile industries are oligopolistic industries with a small number of automakers competing in multiproduct pricing. The markup pricing tends to under-provide the goods relative to the perfectly competitive equilibrium. On the other hand, the negative externality associated with vehicle emissions implies that the market equilibrium tends to over-provide the goods relative to the social optimum. Which of the effects tends to dominate is largely an empirical question. In this context, vehicle tax reforms must take into account its effect on extensive margins. Green car tax reforms often effectively

\footnotetext{
${ }^{1}$ The result assumes homogeneity of consumer preferences. With heterogeneous consumers, the separate car and gasoline taxes can only achieve the second-best (or ex ante) optimum (see Fullterton and West, 2002).

${ }^{2}$ Gasoline taxes in many countries are set either substantially higher or lower than the estimated negative externality cost (Ley and Boccardo, 2010).
} 
subsidize purchase of new or more fuel efficient cars, either relative to the pre-existing tax system or the efficient benchmark, which may result in a perverse entry-inducing effect (Baumol, 1988). Such an entry-inducing effect might be potentially very large in countries where there are a large pool of potential car owners. ${ }^{3}$ Whether such an entry-inducing effect improves efficiency depends largely on the pre-existing market conditions.

This manuscript attempts to empirically investigate the economic impacts of vehicle taxation on social welfare and vehicle $\mathrm{CO}_{2}$ emissions in these second-best settings. To this end, we employ the random-coefficient discrete-choice model, also known as the BerryLevinsohn-Pakes (BLP) estimator. The BLP estimator was developed in Berry (1994) and Bery, Levingsohn, and Pakes (1995), and has been successfully applied in a number of empirical studies since then (e.g., BLP, 1999; Nevo, 2001; Petrin, 2002; Villas-Boas, 2007). The approach makes use of market-level data only (so does not require consumer-level data), and deals with endogeneity of prices, yet allows for heterogeneity in consumer tastes for product characteristics, and hence, generates rich and realistic substitution patterns. ${ }^{4}$ For estimation of the model, we make use of detailed market-level data on sales by car brand and quantifiable car characteristics in the Japanese new car market between 2007 and 2012. We focus on the Japanese new car market, as it offers several attractive features for our purpose. The market is characterized by an oligopolistic industry with nine domestic automakers. The Japanese pre-existing taxation system consists of both a gasoline tax and a suit of vehicle taxes based on car characteristics. Most importantly, the Japanese government started a series of subsidy and tax incentive programs for low-emission, fuelefficient cars, called Ecocar Subsidy (ES) and Ecocar Tax Credits (ETC), since 2009. Their unique features created large exogenous variations in the effective prices of cars across brands and over time.

We exploit this quasi-experimental setup to consistently estimate the structural parameters of the consumer demand for new passenger cars, and then use them to simulate the policy-induced effects on expected annual vehicle $\mathrm{CO}_{2}$ emissions and social welfare. First, we take advantage of the policy-driven large variation in the effective car prices across car brands and over time to obtain the consistent estimates of own- and crossprice elasticities not only among the large number of car brands but also with respect to the outside option. This allows us to distinguish between the effect of inducing more

\footnotetext{
${ }^{3}$ For example, in Japan, a large number of driver's license holders in urban areas are 'paper drivers' with no car ownership because reliable public transportation systems and high parking costs induce them to be so, yet they still hold the licenses as their primary ID cards.

${ }^{4}$ Its main drawback has been the computational burden and numerical accuracy, as it requires running a nested fixed point (NFP) algorithm as an inner-loop subroutine for the generalized method-of-moments (GMM) estimation. To circumvent some of the computational problems, we take advantage of recent advances in the study of the BLP estimator (Dube et al., 2012; Knittel and Metaxoglou, 2012).
} 
consumption (called the scale effect hereafter) and the effect of inducing substitution into more ecofriendly cars (called the composition effect hereafter). Consequently, we are able to make more accurate inferences about the impacts of the policy against the counterfactuals. Second, we exploit the exogenous changes in the tax rates as instruments to take care of the price endogeneity. Implementation of the BLP estimator requires a set of instruments for identification of parameter estimates. Earlier studies often used the 'location' of observed product characteristics in the product space as instruments, arguing that such product-location variables are at least predetermined prior to the determination of consumer demand. Though this may be a valid assumption in some contexts, there are growing concerns with the validity of the assumption. In our context, the location of observed product attributes may be highly correlated with brand images (e.g., Toyota Prius' brand image may come from its high fuel efficiency). Moreover, sales subsidiaries of the automakers tend to offer a variety of sales promotions based on product-specific sales channels. Hence, the location of product attributes may be causally correlated with the measurement errors in observed prices. Indeed, our earlier estimation runs have revealed a number of concerns with the validity of the traditional IVs. We circumvent these concerns by constructing variables that represent the location of vehicle tax rates in the characteristics space in a manner analogous to the product location variables. The vehicle taxes in Japan are indeed a function of observed product characteristics (i.e., prices, vehicle weight, and displacement size). Hence, they are correlated with prices. Yet, the frequent changes in the location of the effective tax rates over the study period are likely to remove much of the causal link with respect to the unobserved product characteristics such as style and brand images, which presumably stay more or less constant over time. We document the problems we encountered with the traditional IVs in Section 4.2 and report the results that indicate the success of our IVs in Section 6.

Our study contributes to four areas of research. First and foremost, a large body of literature has empirically investigated the impacts of gasoline taxes on the demand for car ownership and utilization. Goldberg (1998) used the U.S. Consumer Expenditure Survey for 1984-1990 to examine the effects of the Corporate Average Fuel Economy (CAFE) Standards on automobile sales, prices, and fuel consumption. She finds empirical evidence that the CAFE standards indeed worked as an implicit tax/subsidy on size of cars, effectively inducing consumers to purchase smaller cars. West (2004) used the same survey data for 1997 but investigated the distributional effects of a variety of fiscal instruments such as gasoline tax, taxes on engine size, and subsidies on new vehicles. Both studies estimated household's joint decision on vehicles and vehicle miles traveled, sequentially applying the nested logit in the first stage and the selection correction model 
in the second stage. Bento et al. (2009) augmented these studies' approach substantially by applying the mixed logit, imposing the cross-equation restrictions implied by Roy's identity between the two stages, and considering not only the new car market but also the used car and scrap markets. These studies rely on household-level micro data, and hence, were able to directly control for household-level idiosyncratic tastes. However, there are limitations to these survey-based studies. First, they often do not control for the potential endogeneity of price due to unobserved product characteristics or measurement errors. Though the use of consumer-level information can help minimize the degree of price endogeneity, unquantifiable product characteristics that researchers cannot observe are likely to remain uncontrolled. Second, these survey-based studies artificially aggregate choices into a smaller number of categories (e.g., small compact, large compact, small SUVs, large SUVs etc), as the number of observed purchases in the survey data is typically very small compared to the number of brands available in the market. This is problematic in our context, as we observe substantial variation in fuel efficiency even within car categories of similar sizes. Hence, such artificial aggregation may result in misleading inferences about the policy impacts. Third, these studies often suffer from small variation in the observed prices of the same car brands over time. In contrast, ours exploits the panel structure from 24 quarters of automobile sales data and the large and persistent policy-induced variation in car taxes to control for the endogeneity of price.

Second, this manuscript complements a growing body of literature that examines the impacts of green vehicle taxation on the composition of new car sales. Klier and Linn (2012) study the impacts of green vehicle tax reforms in France, Germany, and Sweden on new car registrations and the sales-weighted average $\mathrm{CO}_{2}$ emissions rates of the new cars. Gerlagh et al. (2014) examine a similar issue, but use the panel data on $15 \mathrm{EU}$ countries. These studies find that the recent efforts to link vehicle taxes to $\mathrm{CO}_{2}$ emissions or fuel efficiency in European countries successfully reduced the average $\mathrm{CO}_{2}$ intensity of new cars. However, these studies do not explicitly consider the substitution across car brands or to the outside option. As a result, these studies get at the reduced-form impact on the composition effect of tax reforms only and ignores the entry-inducing effect on the aggregate $\mathrm{CO}_{2}$ emissions. Our results indicate evidence for both substantial scale and composition effects of the ES/ETC policy. Though the policy successfully reduced salesweighted average emissions, it also increased total sales substantially. Consequently, the policy-induced reduction in annual $\mathrm{CO}_{2}$ emissions was only $1.6 \%$ relative to no policy scenario.

Third, ours is probably the first attempt to empirically investigate the efficiency property of the vehicle-gasoline tax system (called emissions-based vehicle tax or EVT hereafter) 
in the spirit of Fullerton and West (2002) and Innes (1996) under the second-best settings. In first-best settings, the EVT should only internalize the part of externality costs of vehicle characteristics that are not internalized by a complementary gasoline tax. Because motor vehicles are already heavily taxed in Japan based on their vehicle weights and displacement levels, the EVT policy should offer a rebate based on fuel efficiencies of car brands under the first-best settings. In this sense, the Japanese ES/ETC policy is indeed consistent with the idea of the EVT. In the presence of oligopolists competing in multi-product pricing, however, we do not know whether such a rebate would necessarily improve social welfare over the pre-existing market equilibrium. Our results indicate that albeit its negligible impacts on vehicle $\mathrm{CO}_{2}$ emissions, the ES/ETC policy was indeed welfare-enhancing because it substantially increased total economic surplus (i.e., the sum of compensating variation, industry profits, and tax revenues) relative to no such policy. ${ }^{5}$ We also find that a version of the EVT policy that would add a fuel-efficiency-based tax (instead of a rebate) on top of the ES/ETC policy would in general have reduced vehicle $\mathrm{CO}_{2}$ emissions substantially more, yet still increase the total surplus relative to the no-policy counterfactual.

Lastly, a number of studies have successfully applied the BLP estimator in a variety of empirical contexts: automobile (BLP, 1999; Petrin, 2002), cereal (Nevo, 2001), television (Crawford and Yorukoglu, 2012), and yogurt (Villas-Boas, 2007). All these studies use some cost shifters as the set of instruments to control for price endogeneity. For example, the first three studies use the 'product-location' variables whereas Crawford and Yorukoglu (2012) use firm-level cost data and Villas-Boas (2007) uses input prices interacted with brand fixed effects. In contrast, we offer evidence that like other quasiexperimental studies, constructing a set of location variables based upon institutional or regulatory setups that generate exogenous variation in prices can improve the performance of the BLP estimator substantially.

The rest of the paper is organized as follows. The next section introduces the institutional background of the ES/ETC policies and presents the first cut of the analysis. Section 3 describes the empirical model. Section 4 discusses the estimation and identification strategy. Data and instrumental variables are described in Section 5. Our estimation results are presented in Section 6. Section 7 reports the estimated impacts of the ES/ETC and other counterfactual policies. The last section concludes.

\footnotetext{
${ }^{5}$ In the literature, it is customary to calculate total economic surplus as the sum of consumer surplus, producer surplus, and tax revenues, minus environmental damages. In this paper, however, we only report changes in vehicle $\mathrm{CO}_{2}$ emissions and total economic surplus without quantifying the monetary value of environmental damages associated with $\mathrm{CO}_{2}$ emissions. We do so because estimates of the monetary value are known to vary substantially across studies (see, for example, Tol, 2005).
} 


\section{Institutional Background}

Under the Japanese vehicle taxation system, consumers pay three types of car taxes at the time of new car purchase and during the car ownership. First, automobile acquisition tax is a prefectural ad valorem tax, which charges $5 \%$ of the sales value at the time of car purchase. Second, vehicle weight tax is a national tax collected at the time of car inspections every 1-3 years, and was set at 12,600 yen (or 10,000 yen) per ton of vehicle weight before (or after) April of 2010. Third, annual automobile tax is another prefectural tax imposed on car ownership, which ranges from 0 to 111,000 yen, depending on displacement level. There are a special class of cars called Keijidōsha or "minicars" sold in Japan: i.e., extremely small vehicles with displacement level of $660 \mathrm{cc}$ or less. These minicars are exempt from the annual automobile tax. The last two taxes are taxes on ownership, but consumers also pay them at the time of car registration. ${ }^{6}$

Prior to 2009, these car taxes were only tied to vehicle weights, displacement levels, and sales values of cars, and hence, were not explicitly linked to either fuel efficiency or emissions performance. In 2009, partly backed up by then Prime Minister Aso's Green New Deal, the Japanese government started to implement a series of policy experiments on the taxation of automobiles. The policy roughly consists of the Ecocar Tax Credits (ETC) program and the Ecocar Subsidy (ES) program. The ETC offered a variety of tax incentives based on fuel efficiency and emissions performance. For example, models exceeding the 2010 fuel efficiency standard by $15 \%$ (but less than 25\%) and receiving a fourstar rating on the 2005 emissions standard would receive a $50 \%$ cut on vehicle weight tax, a $50 \%$ cut on acquisition tax, and a $25 \%$ cut on annual automobile tax. ${ }^{7}$ The ETC program was originally scheduled to continue until March 31, 2012 (April 30, 2012 for vehicle weight tax), but was extended (in March, 2012) to April, 2015. The ES program, on the other hand, offered a cash rebate of 100,000 $(50,000)$ yen for purchase of a passenger car (mini-car) if it achieves 15\% above the 2010 fuel efficiency standard and the four-star rating on the 2005 emissions standard. ${ }^{8}$ Initially, the ES program was scheduled to last until March 31, 2010. However, it was extended to September 30, 2010, as part of the 2010 economic stimulus package. Furthermore, the second phase of the ES program was re-

\footnotetext{
${ }^{6}$ On top of these car taxes, the consumers also need to pay the $5 \%$ ad valorem sales tax, which did not change throughout the study period.

${ }^{7}$ To be more precise, the tax incentive on the automobile tax started in April, 2004 before the ETC program, and its eligibility requirements have been changing over time. The text refers to the requirements for cars sold in FY2009.

${ }^{8}$ The cash rebate is increased to $250,000(125,000)$ yen for purchase of a passenger car (mini-car) if it replaces old cars aged 13 years or more and meets the 2010 fuel efficiency standard. Because an average year of car ownership in Japan is substantially less than 13 years, we ignore this complication in our analysis.
} 
implemented in December 20, 2011 and continued until January 31, 2013. The eligibility requirements in the second phase were made stricter than those in the first phase. Table 1 summarizes the eligibility requirements for different ES and ETC programs.

[Table 1. Model Eligibility Requirements for ES and ETC]

An attractive feature of the policy initiative for our analysis is that the frequent policy changes and the resulting variation in eligibility requirements for different tax cuts provide important exogenous variations in the effective car tax rates over time and across car brands. Note, first, that this policy period can be further subdivided into three distinct periods: (i) April, 2009 - September, 2010 in which ETC and the first phase of ES were in place; (ii) October, 2010 - December, 2011 in which only ETC was in effect; and (iii) January, 2012 - December, 2012 in which ETC and the second phase of ES were in effect. More importantly, because these ES/ETC programs were tightly linked to fuel efficiency, it allowed the car taxes to be closely linked to the carbon emissions rates of the vehicles. Figure 1-(a) shows the scatter plots of the car taxes against the corresponding carbon emissions rates for all car brands sold during the pre-policy period (January, 2007 - March, 2009) and during the policy period (April, 2009 - December, 2012). The figure demonstrates that the linkage between the car taxes and the emissions performance of the cars became much tighter during the policy period than during the pre-policy period. This is also confirmed with Figure 1-(b), which plots the kernel density of car taxes. Prior to the policies, dispersion in car taxes is relatively small, with the mode of the distribution around 180,000 yen. During the policy period, the distribution of car taxes is more disperse, and some of the car brands even received negative tax rates due to the ES program.

[Figure 1. Regulatory Changes in Car Taxes in Japan]

The ES/ETC policy created a substantial intertemporal variation in vehicle tax rates. Figure 2-b shows the trend in average tax rates (incorporating the subsidy and the tax credits). The average tax rate sharply dropped during the first policy subperiod. ${ }^{9}$ It then increased slightly during the second policy subperiod due to the temporary suspension

\footnotetext{
${ }^{9}$ The average tax rate was calculated as a simple unweighted average over all car models sold during each time period.
} 
of the ecocar subsidy, and then decreased again during the third subperiod when the second phase of the ES was implemented. The policy's impacts on the sales mix and the total sales are less clear-cut. A casual look at the sales patterns over time suggests that these changes in tax rates may appear to have induced substantial behavioral changes in terms of both aggregate consumption and substitution patterns across models. First, Figure 2-c shows that the share of hybrid cars in the total car sales increased dramatically during the first policy subperiod, and the trend continued throughout the policy period. ${ }^{10}$ Moreover, the distribution of sales by fuel efficiency seems to have shifted substantially from less fuel efficient cars to more fuel efficient cars between 2007 and 2012, as evident from Figure 3. Second, total sales quantity (detrended by regressing it on quarter dummies) also jumped dramatically during the first policy subperiod, and then dropped sharply after the ES was ceased. However, there are clear confounders during the study period. The gasoline price (deflated using consumer price index) also increased substantially during the same period (see Figure 2-a), which must have also induced consumers into buying fuel efficient cars. The impact on the total sales is also somewhat ambiguous because the Japanese economy went through two substantial macroeconomic shocks during the study period (the financial crisis, known as the Lehman Shock, and the 2011 Tohoku Earthquake). The effects of these two macroeconomic shocks appear particularly evident during 2008/Q3 - 2009/Q1 and during 2011/Q1 - 2011/Q2. Hence, to get at the causal impacts of the policy, we need to estimate the automobile demand controlling for these time-varying factors.

[Figure 2. Trends in Gasoline Price, Car Prices, Car Tax Rates, New Car Sales, and Hybrid Shares from 2008 to 2012]

[Figure 3. Distribution of Fuel Efficiency in 2007 and 2012]

There may be a concern that some consumers might have shifted their consumption in anticipation of future policies. Such an intertemporal substitution of car purchase may complicate the identification of the policy effects. In our case, however, the effect seems negligible. The ES/ETC policy was announced in April, 2009 and administered in June,

\footnotetext{
${ }^{10}$ In Japan, diesel-based cars represent a tiny fraction of the total sales. Instead, hybrid cars such as Toyota Prius and Honda Civic Hybrid are more closely equated with "eco-friendly" cars in the minds of Japanese consumers.
} 
2009, yet covered cars purchased in April and May, 2009. Moreover, the ES program was initially scheduled to end in March, 2010, but was unexpectedly extended to September, 2010. The second ES period was also similar. It was adopted on December 20, 2011 and started its administration in April, 2012, but covered cars purchased since December 20, 2011. Figure 4 shows the (detrended) trends in monthly new car sales from 2008 to 2010. The sales amount and seasonal pattern were quite stable before and after the first ES program. Although the sales were relatively lower at the beginning of 2009 compared to the same period in the previous years, the trend actually continued until the end of the second quarter of 2009.

[Figure 4. Trends in Monthly New Car Sales from 2008 to 2010]

\section{Empirical Framework}

\subsection{Consumer}

Let us first start with a generic empirical framework, building upon the extensive literature on discrete choice models of automobile demand. In each quarterly market $t$, the indirect utility of consumer $i$ choosing alternative $j$ depends on both observable and unobservable product and consumer characteristics:

$$
u_{i j}(\boldsymbol{\theta})=\delta_{j}(\boldsymbol{\theta})+\mu_{i j}(\boldsymbol{\theta})+\epsilon_{i j}
$$

where $\theta$ is a vector of parameters to be estimated. The first term $\delta_{j}$ only depends on product characteristics (either observable or observable) and is common to all individuals. The second term $\mu_{i j}$ depends on consumer attributes and observed product characteristics and captures heterogeneity in consumer tastes for observed product characteristics. The last component $\epsilon_{i j}$ is the mean-zero random utility and is assumed to be independently and identically distributed.

Much of the recent advance in the literature centers on how to incorporate the term $\mu_{i j}$ in estimation of automobile demand. If this term is not included, the only consumerlevel heterogeneity comes from the i.i.d. error $\epsilon_{i j}$, and hence, the choice probability for any consumer only depends on observable product characteristics $\delta_{j}$. The most unappealing implication of the omission is the unrealistic substitution pattern à la McFadden's red bus/blue bus problem. When consumer-level data are available, the observed choice 
probabilities of new purchasers can be directly linked to their household and product attributes. Goldberg (1995b) and Bento et al. (2009) follow this approach. When only market-level data are available, however, we cannot directly link these two. A usual approach to overcome this problem has been to somewhat artificially segment choices into mutually exclusive groups and decompose the error $\epsilon_{i j}$ into the one common to all groups and another group-specific component (e.g., nested logit), until Berry, Levinsohn, and Pakes (BLP, 1995) proposed an alternative approach. The BLP approach is to assume that the consumer-level taste variation arises from some known distribution such as multivariate normal (BLP, 1995) and $\chi^{2}$ distributions (Petrin, 2002). Then the observed market shares are matched with the model's predicted choice probabilities to consistently estimate the parameters of the term $\mu_{i j}$. To further improve the precision of the BLP estimators, Nevo (2001) and Petrin (2002) independently offered methods to link the aggregatelevel demongraphics of consumers to the characteristics of the products. We do not follow Nevo or Petrin's approach in this manuscript, since in our data we do not have enough variation in, or enough information on, aggregate-level consumer demographics across quarterly markets to implement their approaches.

More specifically, we assume the following utility specification:

$$
u_{i j}=\alpha_{i}\left(y_{i}-p_{j}^{e}\right)+\mathbf{x}_{j} \boldsymbol{\beta}_{i}+\xi_{j}+\epsilon_{i j}
$$

where $p_{j}^{e}=\left(1+\tau_{j}\right) p_{j}$ is the effective (i.e., tax-inclusive) price of car $j, \mathbf{x}_{j}$ the K-dimensional vector of observable characteristics of car $j, \xi_{j}$ the unobservable characteristics of car $j, y_{i}$ the income of individual $i$, and $\left(\alpha_{i}, \boldsymbol{\beta}_{i}\right)$ is a vector of 'random coefficients' to be estimated and assumed to vary over individuals. ${ }^{11}$ Following BLP $(1995 ; 1999)$ and Nevo $(2000$; 2001), we assume that:

$$
\left(\begin{array}{c}
\alpha_{i} \\
\beta_{i}
\end{array}\right)=\left(\begin{array}{c}
\alpha \\
\beta
\end{array}\right)+\Sigma \circ \boldsymbol{v}_{i}
$$

where $\boldsymbol{\Sigma}=\left(\sigma_{p}, \sigma_{1}, \ldots, \sigma_{K}\right)^{\prime}$ is a $(K+1)$-dimensional (row) vector of parameters and $\boldsymbol{v}_{i}$ is a $(K+1)$-dimensional (row) vector of unobservable characteristics of individual $i$. The number of dimension $K$ is equal to the number of variables in $x_{j}$. We assume that $\boldsymbol{v}_{i}$ follows an i.i.d. standard multivariate normal $N(\mathbf{0}, \mathbf{I})$, following BLP $(1995 ; 1999)$. This implies that the marginal utility from $k$-th product characteristic has a mean $\beta_{k}$ and a standard deviation $\sigma_{k}$. For this reason, $\beta_{k}$ is often called a mean parameter and $\sigma_{k}$ is called a standard deviation parameter in the literature.

Note that the term $\xi_{j}$ represents product attributes that are observed by consumers

\footnotetext{
${ }^{11}$ For notational simplicity, we suppress index $t$ because the model is identical for all quarterly markets.
} 
and firms but are unobservable or unquantifiable by the researcher. One way to interpret the term $\xi_{j}$ is that it measures brand images, style, and prestige. Another way to interpret it is that it represents the measurement errors in observed market prices such as productspecific sales promotions and marketing strategies. Either way, it is likely to be correlated with $p-$ e.g., consumer demand is higher for products with better brand images, and measurement errors with respect to prices are likely to be related to sales promotions and sales channels. Hence, if uncontrolled, it is likely to bias our parameter estimates. We take the estimation strategy proposed by BLP $(1995 ; 1999)$ to take care of this endogeneity, which we shall turn to in Section 4.

The discrete choice model is closed with the inclusion of an outside option. In each period, the consumer is assumed to buy at most one car, and may choose to buy one of the $J_{t}$ brands or not buy any car $(j=0)$. In the latter case, she may choose to use public transportation or continue to use a car she already owns. The inclusion of the outside option allows us to estimate the impact of an homogenous decrease or increase in the effective prices of all brands on quantities purchased. Given our specification in (1), the indirect utility from the outside option is given by

$$
u_{i 0}=\alpha_{i} y_{i}+\sigma_{0} v_{i 0}+\epsilon_{i 0}
$$

Note that the term $v_{i 0}$ still needs to be included, despite that there are no observable attributes for the outside option, to account for the possibility that the idiosyncratic variance for this option may be larger than that for the 'inside' goods. In practice, however, the coefficient $\sigma_{0}$ cannot be identified since it cannot be separated our from the standard deviation coefficient on the constant term. Hence, the standard practice is to set $\sigma_{0}$ to equal zero. Because we assume a linear income effect in (1), the term $\alpha_{i} y_{i}$ eventually vanishes. Thus, setting $\sigma_{0}$ to equal zero is equivalent to normalizing the indirect utility from the outside option to zero (see Nevo $(2000 ; 2001)$ for a detailed discussion on this point). With this normalization, the idiosyncratic differences in tastes for the outside option is subsumed in the standard deviation parameter on the constant term. Hence, if we expect different consumers to behave differently with respect to the outside option, say, due to differences in access to public transportation or in the ownership of cars, then we should expect the standard deviation parameter on the constant term to be statistically significant, because the unobservable consumer attributes $\boldsymbol{v}_{i}$ are assumed to include things like access to public transportation, car ownership, commuting distance, and environmental awareness - information that is hard to obtain even in detailed household surveys.

Assuming that $\epsilon_{i j}$ are i.i.d. with a Type-I extreme value distribution, the market share 
of brand $j$ is given by

$$
s_{j}=\int \frac{\exp \left(\mathbf{x}_{j} \boldsymbol{\beta}_{i}-\alpha_{i} p_{j}^{e}+\xi_{j}\right)}{1+\sum_{r=1}^{J_{t}} \exp \left(\mathbf{x}_{r} \boldsymbol{\beta}_{i}-\alpha_{i} p_{j}^{e}+\xi_{r}\right)} d P(\boldsymbol{v}) .
$$

where $P(\cdot)$ is the population distribution of the individual attributes $v \cdot{ }^{12}$ One important aspect of the expression is that the unobserved product attribute $\xi_{j}$ is not integrated out. It is this term that allows for a difference between the predictions of the model (based on observed attributes and estimated parameters) and the observed market shares.

Two caveats on this specification are in order. First, our utility specification slightly diverges from that of BLP $(1995 ; 1999)$ and excludes the nonlinear income effect. In this sense, ours is similar to that in Nevo $(2000 ; 2001)$. If we are to include the nonlinear income effect, we would either take $\log \left(y_{i}-p_{j}^{e}\right)$ or make $\alpha_{i}$ inversely proportional to income $\alpha_{i}=\alpha / y_{i}$ in (1). We chose this specification because our earlier attempts to estimate such a model resulted in either insignificant or positive price coefficients. Second, we also diverge from Nevo in that we do not interact the random-utility terms with observable demographic variables. We chose to do so for two reasons. First, identification of interaction parameters would require variation in the distribution of demographic variables over different markets, yet we found there was very little variation during the study period. In contrast, Nevo was able to use variation across cities as additional source of variation. Second, we had to estimate the model with a much larger number of brands (150-160 brands per market) than Nevo's study ( 25 brands). Thus, we concluded that litthe variation in the distribution of demographic variables compared with a larger number of brands would result in inefficient estimates of the parameters. Indeed, our trial runs with different sets of demographic variables resulted in non-convergence of the estimation algorithm.

\subsection{Producer}

There are $F$ firms in all markets and each firm produces a subset of the products $\mathcal{J}_{f}$. In each quarterly market $t$, the profits of firm $f$ are given by:

$$
\sum_{j \in \mathcal{J}_{f}}\left(p_{j}-m c_{j}\right) M s_{j}\left(\mathbf{p}^{e}\right)-F C_{f},
$$

\footnotetext{
${ }^{12}$ The integral is only with respect to $v$ because $y_{i}$ vanishes in the linear income specification.
} 
where $s_{j}$ is the market share of brand $j$ as defined in (3), $\mathbf{p}^{e}$ is the vector of effective, taxinclusive prices defined as $p^{e}=(1+\tau) p, m c_{j}$ is the marginal cost of each brand $j, M$ is the market size of the new car market, and $F C_{f}$ is the fixed cost of production.

Assuming that firms compete in the Bertrand manner and the unique pure-strategy Bertrand-Nash equilibrium exists (as in BLP, 1995, 1999 and Nevo, 2000, 2001), the price of each brand $j$ satisfies the following first-order condition:

$$
s_{j}\left(\mathbf{p}^{e}\right)+\left(1+\tau_{j}\right) \sum_{k \in \mathcal{J}_{f}}\left(p_{k}-m c_{k}\right) \frac{\partial s_{k}}{\partial p_{j}}=0 .
$$

For each market, this set of $J$ equations determines the optimal markup for each brand. These markups can be solved explicitly a la Nevo (2001). Let us define the matrix $\Omega$ such that each element of $\Omega$ is defined as $\Omega_{j k}=O_{j k} * D_{j k}$, where $O_{j k}$ is the matrix describing the ownership structure:

$$
O_{j k}=\left\{\begin{array}{cc}
1 & \text { if } \exists f:\{j, k\} \in \mathcal{J}_{f} \\
0 & \text { o.w. }
\end{array},\right.
$$

and $D_{j k}$ is the matrix of share derivatives with respect to prices, multiplied by $-1: D_{j k}=$ $-\partial s_{k} / \partial p_{j}$. Then the first-order condition implies:

$$
\mathbf{m c}=\mathbf{p}-\Omega^{-1} \mathbf{s}^{e}\left(\mathbf{p}^{e}\right),
$$

where $\mathbf{s}^{e}$ is a vector of market shares adjusted for tax rates: i.e., the $j$-th element of $\mathbf{s}^{e}$ is $s_{j}^{e}=s_{j} /\left(1+\tau_{j}\right)$.

Once we obtain the consistent estimates of demand parameters, we can estimate the price-cost margins or the marginal costs using (4), which can then be used to simulate the policy-induced effects on industry profits. This strategy was also taken in Nevo (2001). One could impose further structures on the supply relationship, and the cost parameters could then be jointly estimated with the demand parameters. For example, BLP (1995; 1999) consider the estimates of $m c_{j}$ 's obtained from (4) as a log-linear function of cost shifters such as observed product attributes, wages, and unobservable product attributes and estimate the cost parameters jointly with the demand-side parameters. Such a strategy would improve the efficiency of the estimates, but at the cost of imposing more structures and increasing computational burden. As we do not directly make use of the cost side parameters in our simulation analysis, we shall take Nevo's approach to avoid undue complexity. 


\section{Empirical Strategy}

\subsection{Estimation}

For estimation of the model, we closely follow the methods proposed in BLP (1995) and its detailed explanation offered in Nevo (2000). Suppose we have data on a set of exogenous instruments $\mathbf{z}$ such that the unobserved product attributes are mean independent of $\mathbf{z}$ :

$$
E[\boldsymbol{\xi}(\boldsymbol{\theta}) \mid \mathbf{z}]=0 .
$$

This gives us a set of population moment restrictions. Then the generalized method of moments (GMM) estimates of the parameters are:

$$
\hat{\boldsymbol{\theta}}=\arg \min _{\boldsymbol{\theta}} \xi(\boldsymbol{\theta})^{\prime} \mathbf{z} \Omega^{-1} \mathbf{z}^{\prime} \xi(\boldsymbol{\theta}),
$$

where $\Omega$ is a consistent estimate of $E\left[\mathbf{z}^{\prime} \xi \xi^{\prime} \mathbf{z}\right]$, which is used to weight moments in accordance to their variance.

A question remains as to how we might obtain $\xi$, which by assumption is unobservable to researchers. A key here is to recognize that $\xi_{j}$ can be considered as an unobservable error in the mean utility $\delta_{j}$. To see this point, rearrange terms in (1). We then obtain explicit expressions for the mean utility $\delta_{j}$ and the idiosyncratic utility $\mu_{i j}$ :

$$
\delta_{j}(\boldsymbol{\theta})=-\alpha p_{j}^{e}+\mathbf{x}_{j} \boldsymbol{\beta}+\xi_{j} ; \quad \mu_{i j}(\boldsymbol{\theta})=-\sigma_{p} v_{p} p_{j}^{e}+\sum_{k=1}^{K} \sigma_{k} v_{i k} x_{j k} .
$$

As long as we have a consistent estimate of $\delta_{j}$, we can obtain the consistent estimate of $\xi_{j}$ by simply running a linear regression of the estimate of $\delta_{j}$ on product attributes. In the simple logit model, this can be done easily because $\delta_{j}=\ln \left(S_{j}\right)-\ln \left(S_{0}\right)=x_{j} \beta-\alpha p_{j}^{e}+$ $\xi_{j}$, where $S_{j}$ and $S_{0}$ are the observed market shares of brand $j$ and the outside option, respectively. In our case, however, $s_{j}$ is given by (3) and is a nonlinear function of the $\left(x_{j}, p_{j}^{e}\right)$. BLP (1995) proposed a nested fixed point (NFP) algorithm to numerically solve for $\xi$. Let $s_{j}$ be the market share function defined by Eq. (3). Then the value of the mean utility term $\delta$ can be solved numerically by the contraction mapping: ${ }^{13}$

$$
\delta^{h+1}=\delta^{h}+\ln (S)-\ln \left(s\left(\delta^{h} \mid \theta\right)\right) \text { for } h=1, \ldots H .
$$

Thus in essence, the estimation is done by repetition of the two-step procedure. First, given the initial guess of the parameters $\hat{\theta}_{0}$, run the NFP algorithm to get the estimate

\footnotetext{
${ }^{13} \mathrm{BLP}(1995)$ also offers a proof of the convergence of this NFP algorithm.
} 
of $\hat{\delta}_{0}$ and obtain the estimate of the error $\hat{\xi}_{0}$ (this is the "inner loop" of the estimation). Second, solve the optimization program (6) to get the estimate of $\theta$. We repeat the process until the optimization routine achieves desired tolerance. Our estimation is done by carefully modifying the Matlab code supplied at Nevo's website. ${ }^{14}$ The standard errors of the GMM estimator are also computed using Nevo's code, which follows the standard asymptotic variance-covariance formula discussed in Newey and McFadden (1994).

Recently, however, studies have found important problems with implementation of the NFP algorithm and the resulting estimates (see Dube et al. (2012) and Knittel and Metaxoglou (2012) for a more detailed review of such issues). In particular, Dube et al. showed that use of loose tolerance criteria for the inner-loop algorithm to ease the computational burden may result in (i) failure of the optimization program to converge or (ii) the optimization finding parameter estimates that are not even local optima. Indeed, our earlier attempt to directly use Nevo's code revealed both of these problems. To overcome these problems, we adjusted Nevo's original code and used inner-loop tolerance of 1E-14 as suggested by Dube et al. We also replaced Matlab's optimization routine "fminu" with Zeina's KNITRO program, which turned out to be substantially more robust and efficient than "fminu". ${ }^{15}$

\subsection{Identification and Instrumental Variables}

The key to the estimation of the model is a set of instrumental variables required for the moment condition in (5). The common identifying assumption, used in BLP (1995; 1999) and subsequent studies, is that the 'location' of observed product attributes for each brand in the characteristics space is exogenous, or at least predetermined prior to the determination of consumer's valuation of unobserved brand-specific attributes. More specifically, BLP used the observed product characteristics, the values of the characteristics summed over all brands produced by each firm, and the values of the characteristics summed over all brands produced by other firms. Because firms' marginal costs are likely to correlate with their own product characteristics, and because their price markups depend on their product characteristics relative to their competitors, these product-location

\footnotetext{
${ }^{14}$ The modifications include, but are not limited to: allowing the set of products in each market to vary, modifying the inner loop tolerance, replacing the minimization routine, replacing the mean-distance procedure, supplying the code for calculation of own- and cross-price elasticities for both 'inside' and 'outside' goods, and supplying the code for calculation of price-cost margins.

${ }^{15}$ Dube et al. also suggested an alternative algorithm known as a mathematical program with equilibrium constraints (MPEC). We use Nevo's code for our estimation because it was easier for us to flexibly adjust for different specification runs. Our earlier trial with both codes revealed that the estimates were largely similar.
} 
variables are also likely to correlate with prices. On the other hand, because the productlocation variables are at least predetermined at the time of consumers' decisions, they may not be causally related to the unobservable product attributes such as style, prestige, and reputation. This approach has been successfully applied in BLP $(1995 ; 1999)$ and other subsequent studies.

However, there is a growing concern in the literature about the validity of this common identifying assumption - brand images may indeed correlate with the location of observed product attributes. In our case, this concern is even more severe. For example, Toyota's well-known compact-car/hybrid-car strategies suggest that the location of observed attributes such as size and fuel efficiency for their most-selling brands such as Prius and Vitz (known as Yaris in U.S. and Europe) may be highly correlated with unobserved brand images consumers have about these products. In addition, in Japan, some brands are sold exclusively through certain sales channels. For example, Toyota Camry and Vitz, two flagship models, are sold only through stores under the franchises of the Corolla and the Netz, respectively. Because we only observe regular market prices, $\xi$ can also include brand-specific or franchise-specific sales promotions or marketing champaigns, information on which is not readily available to us. Some of the location variables, such as those for size and fuel efficiency, may then be causally related to these unobservable sales promotions. Indeed, our earlier attempt to estimate the RC logit with the traditional IVs resulted in both large GMM objective values and the estimates of price coefficients that are highly sensitive to the random draws $\boldsymbol{v}$.

Given the above concerns, we consider an alternative set of instruments, exploiting the unique quasi-experimental setup in the Japanese new car market. As discussed in Section 2, the series of green tax policies generated exogenous variations in vehicle taxes across brands and over time. Because these taxes are functions of the observable product characteristics (price, weight, and displacement level), they would surely be correlated with prices. On the other hand, the ES/ETC policy caused the effective tax rates to change three times over the study period, which shifted the location of the vehicle taxes in the characteristics space, while the unobserved product characteristics such as style and brand images presumably stayed largely constant. Hence, our tax-location variables are unlikely to be causally related to the unobserved characteristics. Some may argue that though these taxes are not explicitly chosen by automakers or by consumers, automakers might have influenced the design of the policy in favor of some particular brands (e.g., hybrid cars). Even so, the tax rates changed three times over time and across brands during the study period. Hence the frequent changes should minimize the causal link between the unobservable attributes and the tax rates. Therefore, our tax-location IVs would be a 
better instrument, if not perfect, than the traditional IVs. To operationalize this idea, we construct the tax-location variables in a manner analogous to BLP: i.e., tax amounts, the sums of own-firm tax amounts, and the sums of rival-firm tax amounts. Section 6 reports the results of IV and RC logit using the traditional IVs and our tax-location IVs, which indicate the success of our IVs. ${ }^{16}$

\section{Data}

Our data analysis covers the period from January, 2007 to December, 2012. We use the pre-policy period (January, 2007 - March, 2009) as our control period. ${ }^{17}$ We obtained the data on product characteristics and listed prices for all the domestic passenger car brands marketed during this period from Carsensor.Net, one of the largest used car retailer in Japan. ${ }^{18}$ To make our analysis comparable to previous studies, we consider the following major product attributes: the ratio of horsepower to car weight (HP/weight), mileage per yen (MPY), car size (Size), and a dummy indicating whether the model has automatic or continuously variable transmission (AT/CVT). ${ }^{19}$ Information on displacement, emissions performance, and fuel efficiency was also used to determine the ES and ETC eligibility and to calculate MPY, which is the mileage per liter of gasoline divided by the price of gasoline per liter. We treat the same model produced in different time periods as different models: i.e., Honda Accord 2009 versus Honda Accord 2010, as they could be very different due to the rapid technological upgrading. We use the retail sales prices obtained from Carsensor.Net and deflate them by the consumer price index.

The quarterly sales data are obtained from Japan Automobile Dealers Association (JADA). Since we have only the total sales for each model and, in many cases, there are

\footnotetext{
${ }^{16}$ One may argue (correctly) that if we believe $\xi$ represents unquantifiable brand images or measurement errors in observed prices, simply including brand fixed effects in the set of covariates $\mathbf{x}$ might just take care of the concern. The problem with this approach is that if we include brand dummies in the regression, the matrix of $\mathbf{z}^{\prime} \mathbf{z}$ will be essentially singular, as they do not vary across brands and over time. Hence it cannot be inverted. Indeed, we did encounter the problem in our earlier trials. See Nevo (2001) for more detailed discussions on this and related issues.

${ }^{17}$ An earlier draft (Konishi and Zhao, 2014) used Jan., 2004 - Dec., 2012 as the study period but did not include the data on minicars in the analysis. Detailed data on minicar sales are available for only after 2007. Because the minicar sales account for roughly $30 \%$ of the total sales, we decided to use this as our study period.

${ }^{18}$ We hired a doctoral student and two undergraduate students to manually download the catalogue data from the company's website and code the data into excel.

${ }^{19}$ BLP $(1995 ; 1999)$ used a dummy indicating whether the model has air conditioning as a default or not. For our data, this resulted in virtually no variation across models. We thus replaced this variable with the auto transmission dummy. Recently, small-sized cars and hybrid cars increasingly use continuously variable transmission (CVT) to improve fuel efficiency.
} 
many variants (or 'grades') of each model, we obtain the corresponding product attributes and prices by taking the averages over all the variants of the same model marketed in the same time period. We confirmed the validity of this treatment in two ways. First, we were able to obtain detailed used-car sales data by grade for a small fraction of the car brands. We used the data to verify that the majority of sales are concentrated around the variant of the model that has close proximity to the mean attributes. Second, we estimated the IV logit model using the maximum, minimum and median as alternatives, and our major results are quite robust to the different choices.

Besides the data mentioned above, we also make use of some macroeconomic data, such as GDP growth rate, CPI, total number of households, and gasoline prices, which were collected from various sources. The GDP and CPI data are taken from the statistics published by the Cabinet Office of the Japanese government. The data on the number of households are based on the estimates from the Institute of Population and Social Security. The monthly prices of gasoline are from the Institute of Energy Economics in Japan.

Table 2 shows the trends in the sales, prices and major product attribute variables used in our analysis over the study period. The prices and major product attributes are salesweighted means. Around 145-159 car brands were sold in each quarter. Total quarterly sales series clearly displays a seasonal pattern. Car sales are generally strong in the first and the third quarters, followed by drops in the second and the fourth quarters. There are two reasons for this seasonal pattern. First, working individuals usually receive bonuses in June and December, and each bonus is a lump-sum payment approximately twice of their monthly wages. Second, because March is the end of a fiscal year in Japan, sales subsidiaries offer a variety of sales promotions then. After taking into account the seasonal cycle, the sales generally trend downward over time: i.e., the first quarter sales decreased from 1,177,911 in 2007 to 883,547 in 2009 right after the Lehman Shock and further hit the bottom of 807,624 in 2011 due to the Tohoku Earthquake. It started to recover quickly after that, with the first quarter sales reaching 1,355,977 in 2012.

[Table 2. Sales, Price and Product Characteristics of All Brands over Time]

An increasing trend in prices is observed during the study period. The sales-weighted average car prices in 2012 were more than 10\% higher than those in 2007. On the other hand, HP/weight has been fairly constant, but decreased slightly in recent years. MPY first declined from $13.4 \mathrm{~km} /$ yen in 2007 to $10.2 \mathrm{~km} /$ yen in the third quarter of 2008, and then bounced back and reached $17.3 \mathrm{~km} /$ yen in the end of 2012. The downward trend was mainly driven by the increasing price of gasoline, which reached its peak in the third 
quarter of 2008, while the upward trend reflects the improvement in the fuel efficiency of some car brands marketed after 2009. The increasing trend in the MPY is likely to be due to the green vehicle tax policy introduced in the second quarter of 2009. Lastly, the car size and the share of cars equipped with AT/CVT have been roughly constant over time.

Similarly, Tables 3 and 4 provide the summary descriptive statistics for the hybrid cars and minicars only, respectively. It is evident that the sales of hybrid cars have been increasing rapidly, especially after the first quarter of 2009. The market share of hybrid cars became seven times larger from 0.03 in 2008 to 0.21 in 2012. The prices of hybrid cars are generally higher than the average car prices. During 2007, hybrid car prices rose quickly probably because of the increasing demand due to the rising gasoline price. Compared to non-hybrid cars, hybrid cars tend to have lower ratio of horsepower to weight and larger size, but much higher fuel efficiency. Minicars account for approximately one third of the Japanese new car sales. They are generally more compact, less powerful, and cheaper. One take-away message from Tables $2-4$ is that the trends in the key product characteristics did not change dramatically by the introduction of green car tax policies, yet the variety, sales composition, and prices appear to have changed during the policy period.

[Table 3. Sales, Price and Product Characteristics of Hybrid Cars over Time]

[Table 4. Sales, Price and Product Characteristics of Minicars over Time]

\section{Estimation Results}

\subsection{Logit Results}

We first report the results from the OLS and IV Logit models in Table 5. Although these models are known to yield unrealistic substitution patterns (see Nevo, 2001 for a thorough discussion on this point), and hence, are not used to make real inferences about policy impacts, the results give us a sense of the performance of different sets of instrumental variables for use in the full RC logit model. Note that in the logit models, the stochastic error term includes the unobserved product attribute $\xi_{j}$ (so does the random utility term $\mu_{i j}$ ). Therefore, if the set of instruments are correlated with any of these terms, the price coefficients would be biased and the overidentification tests would likely reject the null hypothesis. 
The results are obtained from regressing $\ln \left(S_{j t}\right)-\ln \left(S_{0 t}\right)$ on constants, effective prices, $\mathrm{HP}$ /weight, MPY, size, AT/CVT, year dummies, quarter dummies, and maker dummies, with and without the macroeconomic variable (seasonally adjusted GDP growth rates) to account for the effects of the Lehman crisis and the Tohoku earthquake. ${ }^{20}$ The first two columns in Table 5 report the results from OLS logit, with and without the macroeconomic variables. Columns (III)-(V) display the results of IV logit with different sets of instruments, without the macroeconomic variable. Columns (VI)-(VIII) report the same, but with the macroeconomic variable.

We include quarter fixed effects, because in Japan at least, the car sales has large seasonal effects, particularly in the first quarter and the third quarter (see our discussion in Section 5). This occurs because these correspond to the two bonus seasons and the Japanese automakers put together sales promotions in response. As discussed above, including brand fixed effects in the regression is problematic. We thus instead included maker fixed effects to control for maker-specific brand values (Nevo, 2001).

\section{[Table 5. Estimation Results: OLS Logit and IV Logit]}

For all models, coefficients on MPY, size, and AT/CVT are significant at traditional levels, with signs consistent with our expectation. With the OLS logit, the coefficients on prices are negative and highly significant. With the traditional 'product-location' IVs, however, coefficients on price turn insignificant, whereas with our 'tax-location' IVs, they become highly significant again. HP/weight is not significant with virtually all models (except when our tax-location IVs are used), but this result is indeed consistent with BLP (1995). Comparing models (III)-(V) with models (VI)-(VIII), we see the inclusion of the macroeconomic variable improves the efficiency of estimates and the overidentification test. Importantly, when the 'product-location' IVs are used (i.e., model (VI)), the overidentification test marginally rejects the null, suggesting that some of the IVs are endogenous. A more concerning fact is that with model (VI), the price coefficient is highly insignificant. When our 'tax-location' IVs are used instead (i.e., model (VII)), the overidentification test cannot reject the null even at the 50\% level. We also examine the weak IV problem. Though not reported, all the tax-location IVs are significant at the $1 \%$ level

\footnotetext{
${ }^{20}$ Inclusion of the macroeconomic variable follows BLP (1999). As BLP points out, it is somewhat arbitrary to include such variables. However, the effects of these macroeconomic shocks appear to be very significant, and removing these variables may bias the estimates. An alternative would be to exclude observations from these periods. However, these periods also overlap with policy periods that are important for our analysis. Thus, excluding observations from these periods appears at least as arbitrary as inclusion of macroeconomic variables.
} 
in the first stage regression, and the F-statistic for the test of the explanatory power of these variables is 497.35 , much higher than the conventional cutoff of 10 , suggesting that our IVs are unlikely to suffer from the weak IV problem. On the other hand, with the traditional IVs, many of the own-firm and rival-firm IVs are highly insignificant. We take these as evidence that our 'tax-location' IVs are more reliable than the conventional 'product-location' IVs for our full model.

\subsection{Results of the Full RC Logit Model}

We now report the results of the full RC logit model, with two alternative sets of IVs. For both IVs, we include the same set of variables as model (VII): constants, effective prices, HP/weight, MPY, size, AT/CVT, GDP growth rate, year-quarter fixed effects, and maker fixed effects. Column (IX) reports the result with the traditional 'product-location' IVs whereas column (X) displays the result with our 'tax-location' IVs. As discussed in Section 5, we used inner-loop tolerance for NFP $=1 \mathrm{E}-14$ and outer-loop tolerance for $\mathrm{GMM}=1 \mathrm{E}-3$.

First, the value of the GMM objective is substantially lower with our 'tax-location' IVs than with the traditional IVs. Our GMM objective value is 22E-11, substantially small even compared to the average GMM objective values (178-278, depending on the estimation algorithms used) reported by Knittel and Metaxoglou (2012), who re-estimated the RC model nearly identical to ours using BLP's original auto data. Thus this GMM objective value appears to substantiate the success of our 'tax-location' IVs.

In interpreting the results in Table 6, note that there are in general two ways to explain the effect of each product characteristic. For example, a large-sized car might be popular, either because an average consumer places a high value for the large-sized car (i.e., the effect of the mean utility) or because there is a large variance in consumers' tastes for the large-sized car (i.e., the effect of the distribution of the random utility). ${ }^{21}$ Thus the significance on mean parameters would get at the significance of the former effects whereas that on standard deviation parameters would get at the latter. If we expect any of these variables has significant influence on purchase decision, we should observe at least one of these on each variable is significant.

With the traditional IVs, we observe that all of the mean parameters of the variables (except on HP/weight) are significant at the conventional significance levels, with signs consistent with our expectation. Virtually all of the standard deviation parameters are

\footnotetext{
${ }^{21}$ The logic is well explained in BLP (1995).
} 
insignificant, however. Another reason why we think the traditional IVs do not perform well in our context is because the estimated parameters appeared to be sensitive to both the size and seed of random draws $\mathbf{v}$, the problem we did not encounter with our preferred IVs.

With our preferred IVs, the results are more encouraging. All of the mean parameters are significant at the conventional significance levels with signs in line with our expectation, suggesting that consumers, on average, prefer lower price, higher HP/weight, higher MPY, larger size, and AT /CVT. Not only that, all of the standard deviation parameters are significantly different from zero, suggesting that there are large variations in the tastes for these characteristics. The large standard deviations on HP/weight and AT/CVT suggest that there is a large variation in consumer preferences for these attributes. On the other hand, the standard deviation parameter on price, MPY, and size are small. This implies that though there is indeed some variation in tastes for these attributes, that variation is not large. These results make sense in the context of Japan. Some areas in Japan have very steep hills, for which some consumers may prefer more powerful cars. Yet, in Japan, public roads are notoriously narrow so that a majority of consumers may prefer smaller and less powerful cars for daily operations.

[Table 6. Estimation Results: Full Random-Coefficients Logit]

One well-documented advantage of the RC logit model over simpler logit models is that it gives richer and more realistic own- and cross-price elasticities of demand (Nevo, 2000; 2001). With the simple logit models, own- and cross-price elasticities depend only on the constant parameter, own and cross prices, and observed market shares, which result in (i) nearly constant own-price elasticities and (ii) counter-intuitive substitution patterns that do not take into account similarities between brands. With the RC logit, the own- and cross-price elasticities are instead give by:

$$
\varepsilon_{j k}=\frac{\partial s_{j} p_{k}}{\partial p_{k} s_{j}}=\left\{\begin{array}{ll}
-\frac{p_{j}}{s_{j}} \int \alpha_{i} s_{i j}\left(1-s_{i j}\right) d P\left(v_{i}\right) & \text { if } j=k \\
\frac{p_{k}}{s_{j}} \int \alpha_{i} s_{i j} s_{i k} d P\left(v_{i}\right) & \text { if } j \neq k
\end{array},\right.
$$

where $s_{i j}$ is the choice probability for brand $j$ by individual $i$. In this expression, each individual has a different price elasticities, which are averaged out to yield mean elasticities.

Table 7 displays the sales and product characteristics of the 15 top selling brands as well as the estimated elasticities based on our preferred model $(X)$ for 2011. As expected, 
some of the brands in the table have inelastic demand with respect to own prices because these are top-selling brands with strong brand reputation. The weighted average ownprice elasticity for all brands in 2011 was -1.08 . The estimated elasticities seem roughly comparable to the reported elasticities in BLP (1995), which range from -3 to -4.5 , and in Bento et al. (2009), which range from -0.88 to -1.97 .

The estimated model also allows us to estimate the substitutability of the inside goods to the outside option. We make explicit use of the substitution elasticities to the outside option in identifying the scale effect of the ES/ETS policy. Given an appropriate measure of market size $M$ (with all relevant brands in the data), we examine how the total sales quantity $M\left(1-s_{0}\right)$ would respond to a counterfactual policy scenario. Hence, it is crucial to obtain consistent estimates of the substitution elasticities. The last column of Table 7 reports, à la BLP (1995), the estimated percentage of consumers who substitute to the outside good as a percentage of those who substitute away from a brand, given a price increase for that brand, for top-selling brands in 2011: i.e., $\left(d s_{0} / d p_{j}\right) /\left|d s_{j} / d p_{j}\right| \times 100$. The number essentially indicates, given a small price increase for the brand $j$, of those who decided not to purchase the brand, what percentage of them would choose not to buy any of the brands. As in BLP (1995), the estimated substitution elasticities vary substantially across brands. We emphasize here that these numbers are roughly comparable to those in BLP (1995), yet are smaller than those in BLP (1995). We deem this as evidence of our success in estimation — BLP (1995) note their numbers "still seem a bit large" (p.881).

[Table 7. Product Characteristics, Estimated Elasticities, and Price-Cost Margins of the Top 15 Sales Brands for Year 2011]

Table 8 reports the estimated average own- and cross-price elasticities for these brands for 2011. Each entry $(j, k)$ represents a percentage change of the market share for brand $j$ with respect to a percentage change of the price of brand $k$. The estimated elasticities exhibit expected signs and magnitudes and are roughly comparable with those reported in BLP (1995) on U.S. counterparts. There is also substantial variation across brands, unlike with the standard logit model, which would display the identical cross-price elasticity for all entries in each column. ${ }^{22}$ Many of the top-selling brands in the table had small crossprice elasticities, the magnitudes of which are roughly comparable to those reported in BLP (1995). ${ }^{23}$ Yet, some of the top-selling brands had relatively large cross-price elastic-

\footnotetext{
${ }^{22}$ Note that with the standard logit, the cross-price elasticity formula is $\varepsilon_{j k}=\alpha p_{k} s_{k}$ for all $j \neq k$, instead of Eq. (7).

${ }^{23}$ In BLP (1995), even the brands that had the largest own- and cross-price elasticities exhibited cross-price elasticities that were in the order of $1 / 100$ or smaller relative to their respective own-price elasticities.
} 
ities with respect to each other, particularly to brands with similar characteristics. For example, Prius, Toyota's long-selling hybrid car, had relatively large elasticities with respect to the price of Honda's Fit Hybrid. Note that these cross-price elasticities are highly asymmetric for some of the brands. For example, the demand for Toyota Prius is relatively sensitive to the price of Toyota Vitz, yet the demand for Vitz is not too sensitive to the price of Prius. Interestingly, Honda Fit and Honda Fit Hybrid have small cross-price elasticities with each other, suggesting that they are not perceived as close substitutes despite the fact that the latter is simply a hybrid version of the same brand. This makes sense because these two models indeed have very different product attributes (see Table 7).

[Table 8. Estimated Own- and Cross-Price Elasticities of the Top 15 Sales Brands for Year 2011]

\section{Policy Evaluation}

\subsection{Impacts on Distribution of Fuel Efficiency and Likelihood of Purchase}

We now attempt to quantify the impacts of the ES/ETC policy on vehicle emissions and social welfare relative to the no-policy counterfactual. To this end, we first estimate the effects on the distribution of fuel efficiency and the likelihood of vehicle purchase. As evident from Figure 3, the observed distribution of fuel economy of new car sales, measured in kilometers per liter of gasoline, has changed dramatically during the study period. As discussed in Section 2, however, a number of time-varying factors (including observables such as gasoline price and national income) must have confounded the effects of the ES/ETC policy. Hence, to isolate the pure impacts of the policy, we simulate a no-policy counterfactual in which vehicle taxation were maintained at the pre-policy level during the 2009-2012 policy period. In order to disentangle the effects of the two programs (i.e., ES and ETC), we also construct another counterfactual (called ETC Only) in which only the ETC policy were implemented. We quantify the policy impacts by comparing the outcomes of the two counterfactuals against the predicted (rather than actual) outcome under the ES/ETC policy. ${ }^{24}$

Figure 5 illustrates the estimated policy impacts on the average and distribution of fuel efficiency. The estimated kernel density uses the sales quantity of each brand as the

\footnotetext{
${ }^{24}$ Comparing the counterfactuals against the observed outcomes would be misleading in our context, since the observed outcome would include the effects of unobserved errors whereas the counterfactuals would not.
} 
frequency for each observation. As indicated, the ES/ETC policy shifted the density from less fuel efficient cars to more fuel efficient cars over the four-year policy period. This shift in the distribution also lead to an increase in average fuel economy from $21.13(\mathrm{~km} / \mathrm{L})$ to $21.93(\mathrm{~km} / \mathrm{L}$ ) (or equivalently, $49.70 \mathrm{mpg}$ to $51.58 \mathrm{mpg}$ ). Klier and Linn (2013) report the estimated impact of a $\$ 1$ increase in fuel price per gallon on fuel efficiency in U.S. and Europe to be between 0.15 and $1.30 \mathrm{mpg}$ (see their Table 8). Hence, the estimated impact of the ES/ETC seem fairly large. On the other hand, the observed average fuel economy during the same policy period was only $20.42(\mathrm{~km} / \mathrm{L})$. Use of the observed outcome would have substantially underestimated the policy impacts.

[Figure 5. The Estimated Impacts of the ES/ETC Policy on the Average and Distribution of Fuel Efficiency]

This policy-induced effect on fuel efficiency, however, comes at the cost of inducing more car ownership. Unlike the reduced-form estimation in some other studies (e.g., Klier and Linn, 2013), our structural estimation approach can also simulate the policy impacts on the likelihood of vehicle purchase - i.e., how much more likely are the consumers to buy any car under the ES/ETC policy than under the no-policy counterfactual? In other words, how many more consumers who would not have bought any car in the absence of the policy would buy cars in the presence of the policy. To quantify this policy impact, we calculate $L V P \equiv \sum_{j \neq 0} s_{j}^{\text {Policy }} / \sum_{j \neq 0} s_{j}^{\text {No Policy }}$, where $s_{j}$ is the predicated market share of brand $j$ as defined in (3). Figure 6 plots this measure over the four-year policy period. As indicated, both the ES and the ETC programs had positive impacts on the likelihood of vehicle purchase. Interestingly, there is a substantial intertemporal variation. In general, the impact of the ES policy is larger when the impact of the ETC policy is larger, and the impact of any of the two programs is generally higher when there are other confounding effects such as higher gasoline prices or higher GDP growth. Presumably, this occurs because we allow correlation across choices. That is, when the effective price of a fuel efficient car decreases, a consumer who values such a fuel efficient car is more likely to buy it when, say, the gasoline price is higher than otherwise.

[Figure 6. The Estimated Impacts of the ES/ETC Policy on the Likelihood of Vehicle Purchase] 


\subsection{Impacts on Vehicle Carbon Emissions and Social Welfare}

Next, we attempt to translate these policy-induced demand responses into aggregate vehicle $\mathrm{CO}_{2}$ emissions and social welfare. To that end, we need a good estimate of the expected emissions generated through consumers' utilizaton of purchased cars. Ideally, one would jointly estimate the automobile demand and the demand for driving by combining the market-level and household-level data on car ownership and utilization. Bento et al. (2009) jointly estimate the two types of demand using the household-level data only. Such an approach is defensible only if the household-level data are comprehensive and large enough to allow researchers to make accurate inferences about aggregate marketlevel behaviors. To our knowledge, no such household-level data are available in Japan for our study period. Instead, we exploit a unique feature of the Japanese car owners' driving behavior. As discussed in Online Appendix, the lowess regression on a crosssection sample of 1,371 Japanese car owners in 2013 indicates that their average monthly driving distances do not vary, in a statistically significant way, by fuel efficiency of the cars they own.

Based on the above, we adopt the following measure of (expected) aggregate emissions, in a manner analogous in spirit to Fullerton and Gan (2005) and Klier and Linn (2011). Let $E_{t}$ be the aggregate $\mathrm{CO}_{2}$ emissions generated through consumption of gasoline in utilizing the cars purchased in each market $t$. Then, $E_{t}$ can be approximated by:

$$
E_{t} \simeq \sum_{j \in J_{t}} q_{j t}\left(\frac{E P G \times V M T}{M P G_{j t}}\right)
$$

where for each market $t$ in each quarter, $q_{j t}$ is the sales quantity of car brand $j, M P G_{j t}$ is the expected miles per gallon of gasoline for car brand $j, V M T$ is the expected annual vehicle miles traveled, and EPG is the average $\mathrm{CO}_{2}$ emissions per gallon of gasoline. As in the previous literature (e.g., Innes, 1996), we assume EPG is constant and use the EPA estimate of 8.887 kilograms per gallon (EPA, 2011). For VMT, we use the average annual driving distance of 10,575 $\mathrm{km}$ in Japan (MLITT, 2012). Then, this expression can be simplified to:

$$
E_{t}=\sum_{j=1}^{J_{t}} q_{j t} \varphi_{j t}
$$

where $\varphi_{j t}=(E P G \times V M T) / M P G_{j t}$. This measure essentially asks, How much of $\mathrm{CO}_{2}$ emissions would be emitted from the cars sold during each period $t$ on average? ${ }^{25}$ Albeit

\footnotetext{
${ }^{25}$ The existing literature finds that elasticity of utilization with respect to car prices is small or negligible
} 
its limitation, one advantage of the approximation (8) is that the impact of a policy change can be decomposed into two components:

$$
\Delta \hat{E}_{t}=\left(Q_{t}^{1}-Q_{t}^{0}\right) \bar{\varphi}_{t}^{1}+Q_{t}^{0}\left(\bar{\varphi}_{t}^{1}-\bar{\varphi}_{t}^{0}\right)
$$

where $Q_{t}^{m}=\sum_{j} q_{j t}^{m}$ is the total sales quantity and $\bar{\varphi}_{t}^{m}=\sum_{j} s_{j t}^{m} \varphi_{j t}^{m}$ is the weighted average emissions under policy $m$ in quarterly market $t$, with weight $=$ sales share $s_{j t}^{m}$ for each $j$. The first term is the scale effect, which measures the impact purely of the total sales quantity holding the average emissions rate constant. The second term is the composition effect, which measures the impact of changes in the composition of the total sales.

Quantification of the policy's impacts on consumer surplus, producer surplus, and tax revenues is relatively straightforward. We use, as in previous studies, the compensating variation measure of the changes in effective prices à la McFadden (1981):

$$
C V=\sum_{i} \sum_{j} \frac{\ln \left(\exp \left(u_{i j}\left(\mathbf{p}^{e, m}\right)\right)-\ln \left(\exp \left(u_{i j}\left(\mathbf{p}^{e, m^{\prime}}\right)\right)\right.\right.}{\alpha_{i}} .
$$

Note that this compensating variation measure does not include the negative externality cost of vehicle emissions. We do not quantify the monetary value of the vehicle emissions because the estimates of the marginal economic damages associated with $\mathrm{CO}_{2}$ emissions vary substantially across studies (Tol, 2005). Hence, we report consumer surplus, producer surplus, tax revenues, and vehicle emissions separately, and call the sum of the first three excluding the negative externality costs as the 'total economic surplus'. Producer surplus is computed using (4), assuming no markup response to the policy change.

Making inferences about the policy impacts also requires us to obtain the standard errors of the estimated impacts. Doing so in our context is not easy. We could linearize the policy impacts in the parameters and use the "delta method." However, as the policy impacts are highly nonlinear in the parameters, this approach may not be appropriate. Berry et al. (1999) instead use a Monte Carlo approach, taking draws from the estimated asymptotic normal distribution of the parameters. We took 300 draws of parameters, and calculate the standard deviations of the policy impacts as the estimates of the standard errors.

We first report in Table 9 the estimated aggregate emissions under each policy scenario. We make several important observations. First, the estimated annual reduction in gasoline-consumption-related $\mathrm{CO}_{2}$ emissions from the ETC/ES policy is 65,600 tons or

(e.g., Goldberg, 1998). Thus, the driving distance may not add much to our discussion unless we have detailed information on car utilization that differs in an important way by each car model. 
only $1.6 \%$ of the annual emissions that would have occurred in the absence of the policy. Second, using Eq. (9), we can decompose the impacts into the scale and composition effects. We see that the policy indeed had substantial effects of both. The ETC/ES policy induced consumers into buying more fuel efficient cars. This substitution alone is estimated to have reduced 145,600 tons of $\mathrm{CO}_{2}$ emissions or roughly $3.5 \%$. However, this reduction is largely offset by the scale effect, which increased the total sales of cars by giving incentives for buying cars. The scale effect is estimated to have increased 80,000 tons of $\mathrm{CO}_{2}$ emissions annually or roughly $1.9 \%$ relative to no policy. Third, a somewhat more encouraging observation is that the Japanese government's decision to add the ES policy on top of the ETC policy seemed to have induced a further reduction in aggregate emissions, rather than increasing it.

[Table 9. Decomposition of the Simulated Impacts on Expected Aggregate Emissions from the New Car Sales]

Table 10 reports the simulated impacts of three policy scenarios on aggregate vehicle $\mathrm{CO}_{2}$ emissions, compensating variation, industry profits for domestic automakers, and tax revenues. As expected, the ES/ETC policy had a positive impact on both consumer welfare and industry profits, with increases of 373.9 billion yen and 170.7 billion yen annually relative to no policy. The increase in compensating variation and industry profits more than offset the decrease in tax revenues. Because it also induced a reduction in vehicle $\mathrm{CO}_{2}$ emissions, the ES/ETC policy was indeed welfare-improving. The net effects of the ES program on top of the ETC program are estimated at about 191.6, 136.9, and -207.6 billion yen, respectively, for compensating variation, industry profits, and tax revenues. Hence, the net gain in total economic surplus, excluding that from environmental damages, is positive and estimated to be 120.9 billion yen annually. Hence, the Japanese government's decision to subsidize ecofriendly cars was also welfare-improving.

[Table 10. The Simulated Impacts of the ETC/ES Policy on Aggregate Emissions, Compensating Variation, Industry Profits, and Tax Revenues]

7.3. Emissions-based Vehicle Tax (EVT) 
Given the results so far, another important question arises: Is it possible to improve either the pre-existing vehicle taxation system or the ES/ETC program for greater efficiency? To address this question, we investigate the idea of an emissions-based vehicle tax (EVT) à la Fullerton and West (2002). Consider the following rebate/tax system:

$$
T_{j t}^{E V T}=T_{j t}^{m}+\frac{A}{M P G_{j t}},
$$

where $T_{j t}^{m}$ is the total amount of car taxes under some benchmark tax system $m$ for brand $j$ in period $t, M P G_{j t}$ is miles per gallon, and $A$ is some constant that defines the tax/rebate rate per unit of fuel efficiency. If $A<0(A>0)$, this scheme would add a rebate (tax) based on fuel efficiency on top of the benchmark tax system. We evaluate the impact of varying $A$ for two benchmark tax systems: $m=$ No Policy (i.e., the pre-existing tax system) and $m=$ ES/ETC Policy.

There are several advantages of formalizing the EVT this way. First, as shown in the Appendix, this formulation closely follows the optimal vehicle tax in the spirit of Fullerton and West (2002), provided that an efficient gasoline tax is in place and there is no imperfect competition. With such an interpretation, $A$ must be negative, so that the second component can be considered a rebate on choosing fuel-efficient cars for part of the external costs that is already internalized by a gasoline tax. Second, because the expected annual $\mathrm{CO}_{2}$ emissions from brand $j$ in period $t$ can be approximated by ( $E P G \times$ $V M T) / M P G_{j t}$ (see the discussion above), we can interpret $A>0$ as adding a vehicle carbon tax based on the expected vehicle $\mathrm{CO}_{2}$ emissions. Third, because of other preexisting distortions, the optimal EVT à la Fullerton and West (2002) may not be necessarily welfare-improving. Indeed, whether a rebate $(A<0)$ or a tax $(A>0)$ would work better is an empirical question, which this formulation allows us to conveniently evaluate.

Figure 7 exhibits the simulated impacts of the EVT policy on total surplus and vehicle emissions for varying levels of $A$ under the two benchmark tax systems. As expected, there is a clear tradeoff between total surplus and vehicle emissions. With either reference system, an EVT-rebate policy would generally increase total surplus at the cost of also increasing vehicle emissions. An EVT-tax policy would generally have the opposite effects. As one might expect, however, the total surplus (excluding environmental damages) has a concave relationship to aggregate vehicle emissions. This occurs because aggregate vehicle emissions is monotonically decreasing in $A$ whereas there is a tradeoff between tax revenues and the sum of consumer welfare and industry profits. The estimated gradiant of the curve at the origin (i.e., the no-policy counterfactual) is roughly 8,700 yen per ton of 
vehicle $\mathrm{CO}_{2}$ emissions. ${ }^{26}$ Hence, we conclude that the pure EVT-rebate policy would not have been welfare-enhancing relative to the no-policy counterfactual unless the negative externality cost of carbon emissions is 8,700 yen or lower.

The figure also demonstrates the two unique features of Japan's ES/ETC policy. First, unlike the EVT policy, the ES/ETC policy does not exhibit a simple tradeoff between the total surplus and the vehicle emissions. As a result, the policy outcome (the triangle marker) is far off any points along the EVT curve (the + marker). Second, the ES/ETC policy increased the total surplus with only a small change in vehicle emissions. This occurs presumably because tax rate reductions were varied not only by fuel efficiency but also by other product characteristics (i.e., they vary by sales prices, weights, and displacement levels). Indeed, with the ES/ETC policy as the reference tax system in (10), we see that it is possible to reduce vehicle $\mathrm{CO}_{2}$ emissions substantially while also increasing total economic surplus relative to the pre-existing equilibrium (i.e., no-policy counterfactual). The result of the exercise is illustrated by the dot plot, which demonstrates that this version of the EVT policy exhibits the analogous tradeoff between vehicle emissions and total surplus, yet the trajectory lies strictly above that for the case of the pre-existing tax system as the benchmark.

[Figure 7. Simulated Impacts of Emissions-based Vehicle Tax Relative to Pre-existing Equilibrium, Avg. 2009-2012]

\section{Concluding Remarks}

To investigate the economic impact of green vehicle taxation in second-best settings, a random-coefficients logit model was estimated for quarterly automobile sales data in Japan between 2007 and 2012. We exploited the unique quasi-experimental setup created through a series of green car tax policies in the Japanese new car market in two ways. First, we constructed a new set of instrumental variables, arguing that the location of vehicle taxes over the product space is exogenous. Second, we took advantage of the large and persistent variation in the effective prices of cars that varied across models and over time in identifying the price elasticities. The estimated elasticities were then used to simulate the counterfactual policies and to decompose the scale and composition effects of the policies.

We found evidence that indicate (i) the success of our tax-location IVs and (ii) strong scale and composition effects of the car tax reform. The ES/ETC policy was estimated

\footnotetext{
${ }^{26}$ This calculation assumes an average year of use for the cars sold all years is approximately 10 years.
} 
to successfully shift consumption toward fuel-efficient, ecofriendly cars, resulting in a large decline in the sales-weighted average emissions per vehicle. Yet, the policy also induced more purchase of cars, which had largely offset the composition effect. As a result, the policy-induced overall reduction in $\mathrm{CO}_{2}$ emissions was small. In contrast, a version of the emissions-based vehicle tax policy was shown to reduce vehicle $\mathrm{CO}_{2}$ emissions substantially more, but with lower total surplus, than the ES/ETC policy.

While our study offers several advantages over the previous studies, it also has several important limitations. Addressing them would define new and important agendas for future research. First, due to data limitation, we did not estimate the car ownership and utilization decisions jointly. Recent studies have shown that (i) combining the market-level data with household-level data (BLP, 2004; Petrin, 2004) and (ii) imposing cross-equation restrictions by imposing the Roy's identify for the demand for car utilization (Bento et al., 2009) would improve the consistency and efficiency of the estimates. Second, we did not investigate the effects of the ES/ETC policy on used car and scrap markets. In theory, the policy must have had two counteracting effects. On one hand, the policy would induce consumers into buying new, fuel-efficient cars and, therefore, may facilitate retirement of old, fuel-inefficient cars. ${ }^{27}$ On the other hand, the policy would also induce consumers into buying used cars because it would increase the supply of used cars, thereby decreasing the prices of used cars. Hence, it seems largely an empirical question whether inclusion of used car and scrap markets would increase or decrease the estimated impacts on aggregate emissions. Hence, collecting detailed household-level data on car ownership and utilization as well as detailed used car sales/scrap data and combining them with ours would further improve the accuracy of the estimated impacts of the green car tax reforms.

\footnotetext{
${ }^{27}$ An argument focusing only on this first effect is highly misleading at least in our context. Though we do not have detailed used car sales data by model (except for a small subset of the car models), we have data on aggregate used car sales and scrappage. The correlation between the aggregate new car sales and used car sales is a positive 0.16 during our study period (2004-2012). Moreover, the total scrappage decreased during the same period.
} 


\section{Appendix. A Theoretical Foundation for the Emissions-based Vehicle Tax Policy}

Consider the optimal combination of vehicle and gasoline taxes that would replicate the social optimum in the absence of imperfect competition. Fullerton and West (2002) show that given the efficient gasoline tax, the optimal vehicle tax rate for product attribute $k$ for pollutant $l$ is:

$$
t^{l k}=\lambda^{l} V M T\left[\frac{\partial E P M^{l}}{\partial x^{k}}+\frac{E P M^{l}}{M P G} \frac{\partial M P G}{\partial x^{k}}\right],
$$

where $\lambda^{l}$ is the negative external damage per unit of emissions, EPM ${ }^{l}$ is emissions per mile of driving, and MPG is millage per gallon of gasoline. As Fullerton and West (2002) note, the first term in the bracket times $\lambda^{l} V M T$ represents the environmental damage due to a per-unit increase of attribute $k$, and is positive for most product attributes (e.g., weight, size, and displacement). On the other hand, the second term in the bracket is often negative for most attributes because $\partial M P G / \partial x^{k}<0$. This term is a 'rebate' for part of the external cost that is already internalized by the gasoline tax. Moreover, note that the expression inside the bracket can be rewritten as $\partial E P G^{l} / \partial x^{k}$, where $E P G^{l}$ stands for emissions per gallon of gasoline. This means that there is no need for a separate vehicle tax if we care only about $\mathrm{CO}_{2}$ emissions because $\partial E P G^{\mathrm{CO}_{2}} / \partial x^{k}=0$.

Summing over (A1) for all $k$ and $l$, and evaluating it at the means of the product attributes, we obtain the amount of tax for an automobile with characteristics $\mathbf{x}_{j t}$ :

$$
T^{E V T}\left(\mathbf{x}_{j t}\right)=V M T \sum_{l=1}^{L} \sum_{k=1}^{K} \lambda^{l} \frac{\partial E P M^{l}(\overline{\mathbf{x}})}{\partial x^{k}} x_{j t}^{k}+V M T \sum_{l=1}^{L} \lambda^{l} \frac{E P M^{l}(\overline{\mathbf{x}})}{\operatorname{MPG}\left(\mathbf{x}_{j t}\right)}\left(\sum_{k=1}^{K} \frac{\partial M P G(\overline{\mathbf{x}})}{d x^{k}} x_{j t}^{k}\right),
$$

where $\overline{\mathbf{x}}$ indicates a vector of the means of the attributes.

Note that the first term represents the (sum of) environmental damages from buying a car with attributes $\mathbf{x}_{j t}$. The second term is the rebate for buying a car with fuel efficiency $M P G\left(\mathbf{x}_{j t}\right)$ that is already internalized by the gasoline tax. If we had product-specific emissions data for $\mathrm{CO}, \mathrm{HC}$, and $\mathrm{NO}_{x}$, we would be able to estimate $\partial E P M^{l} / \partial x^{k}$ for each attribute $k$ and replicate this tax perfectly. Unfortunately, we only have data on $M P G\left(\mathbf{x}_{j t}\right)$. Under the pre-existing Japanese vehicle taxation, tax rates vary by vehicle weight and displacement because emissions per unit of fuel for $\mathrm{CO}, \mathrm{HC}$, and $\mathrm{NO}_{x}$ increase with these product attributes. Hence, the tax system may be already incorporating the first component. On the other hand, tax rates do not vary by fuel efficiency under the pre-existing tax system, and hence, it does not incorporate the second rebate component. Based on this 
observation, we approximate $T^{E V T}\left(\mathbf{x}_{j t}\right)$ as follows:

$$
\hat{T}^{E V T}\left(\mathbf{x}_{j t}\right)=T_{j t}^{m}+\frac{A(\boldsymbol{\lambda})}{M P G\left(\mathbf{x}_{j t}\right)},
$$

where $T_{j t}^{m}$ represent taxes under some benchmark taxation $m$ and we evaluate $A(\boldsymbol{\lambda})$ at the means of the attributes, and therefore, is constant:

$$
A(\boldsymbol{\lambda})=V M T \sum_{l=1}^{L} \lambda^{l} E P M^{l}(\overline{\mathbf{x}})\left(\sum_{k=1}^{K} \frac{\partial M P G(\overline{\mathbf{x}})}{d x^{k}} \bar{x}_{j t}^{k}\right) .
$$

Indeed, the ES/ETC policy partly uses this idea because it gives subsidies and tax credits based on fuel efficiency. 


\section{References}

[1] Baumol, William J. 1988. The Theory of Environmental Policy. 2nd Edition. Cambridge University Press: New York.

[2] Berry, S., Estimating Dicrete-Choice Models of Product Differentiation. RAND Journal of Economics, 25 (2), 1994, 242-262.

[3] Berry, S., J. Levinsohn, and A. Pakes, Automobile Prices in Market Equilibrium. Econometrica, 63 (4), 1995, 841-890.

[4] Berry, S., J. Levinsohn, and A. Pakes, Voluntary Export Restraints on Automobiles: Evaluating a Trade Policy. American Economic Review, 89 (3), 1999, 400-430.

[5] Bento, A., L. Goulder, M. Jacobsen, and R. von Haefen, Distributional and Efficiency Impacts of Increased US Gasoline Taxes. American Economic Review, 99 (3), 2009, 667699.

[6] Crawford, G. S. and A. Yurukoglu, The Welfare Effects of Bundling in Multichannel Television Markets, American Economic Review, 102, 2012, 301-317.

[7] Dube, J., J. Fox, and C. Su, Improving the Numerical Performance of Static and Dynamic Aggregate Discrete Choice Random Coefficients Demand Estimation. Econometrica, 80 (5), 2012, 2231-2267.

[8] Feng, Y., D. Fullerton, and L. Gan, Vehicle Choices, Miles Driven, and Pollution Policies. Journal of Regulatory Economics, 44, 2013, 4-29.

[9] Fullerton, D. and L. Gan, Cost-effective Policies to Reduce Vehicle Emissions. American Economic Review, 95 (2), 2005, 300-304.

[10] Fullerton, D. and S. West, Can Taxes on Cars and Gasoline Mimic an Unavailable Tax on Emissions? Journal of Environmental Economics and Management, 43, 2002, 135-157.

[11] Gerlagh, Reyer, I. Bijgaart, H. Nijland, and T. Michielsen, Car Sales in the EU: Fiscal Policy Lowers the $\mathrm{CO}_{2}$ Emissions Intensity, mimeo.

[12] Goldberg, P., The Effects of the Corporate Average Fuel Efficiency Standards in the US. Journal of Industrial Economics, 46 (1), 1998, 1-33.

[13] Innes, R., Regulating Automobile Pollution under Certainty, Competition, and Imperfect Information. Journal of Environmental Economics and Management, 31, 1996, 219-239. 
[14] Klier, T. and J. Linn, Using Vehicle Taxes to Reduce Carbon Dioxide Emissions Rates of New Passenger Vehicles: Evidence from France, Germany, and Sweden. MIT Center for Energy and Environmental Policy Research WP 2012-011.

[15] Klier, T. and J. Linn, Fuel Prices and New Vehicle Fuel Economy - Comapring the United States and Western Europe. Journal of Environmental Economics and Management, 66 2013, 280-300.

[16] Knittel, C. and K. Metaxoglou, Estimation of Random Coefficients Demand Models: Two Empiricists' Perspectives. 2012, mimeo.

[17] Ley, .E. and J. Boccardo. The Taxation of Motor Fuel: International Comparison. World Bank Policy Research Working Paper 5212.

[18] Nevo, A., A Practitioner's Guide to Estimation of Random-Coefficients Logit Models of Demand. Journal of Economics and Management Strategy, 9 (4), 2000, 513-548.

[19] Nevo, A., Measuring Market Power in the Ready-to-Eat Cereal Industry. Econometrica, 69 (2), 2001, 307-342.

[20] Petrin, A., Quantifying the Benefits of New Products: The Case of the Minivan. Journal of Political Economy, 110 (4), 2002, 705-729.

[21] Tol, R.S.J., The Marginal Damage Costs of Carbon Dioxide Emissions: An Assessment of the Uncertainties. Energy Policy 33, 2005, 2064-2074.

[22] Villas-Boas, S., Vertical Relationships between Manufacturers and Retailers: Inference with Limited Data. Review of Economic Studies. 74 (2), 2007, 625-652.

[23] West, S., Distributional Effects of Alternative Vehicle Pollution Control Policies. Journal of Public Economics, 88, 2004, 735- 757. 
Figure 1. Regulatory Changes in Car Taxes in Japan

(a) Car Taxes vs. $\mathrm{CO} 2$ Emissions Rates

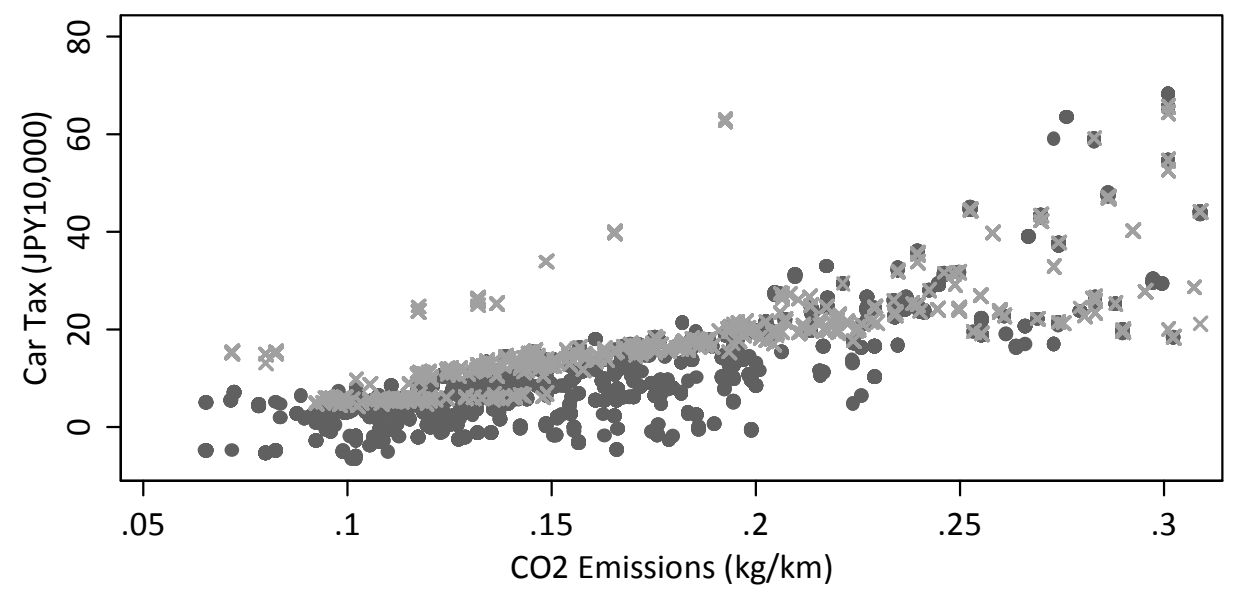

- Policy Period $\times$ Control Period

(b) Distribution of Car Taxes

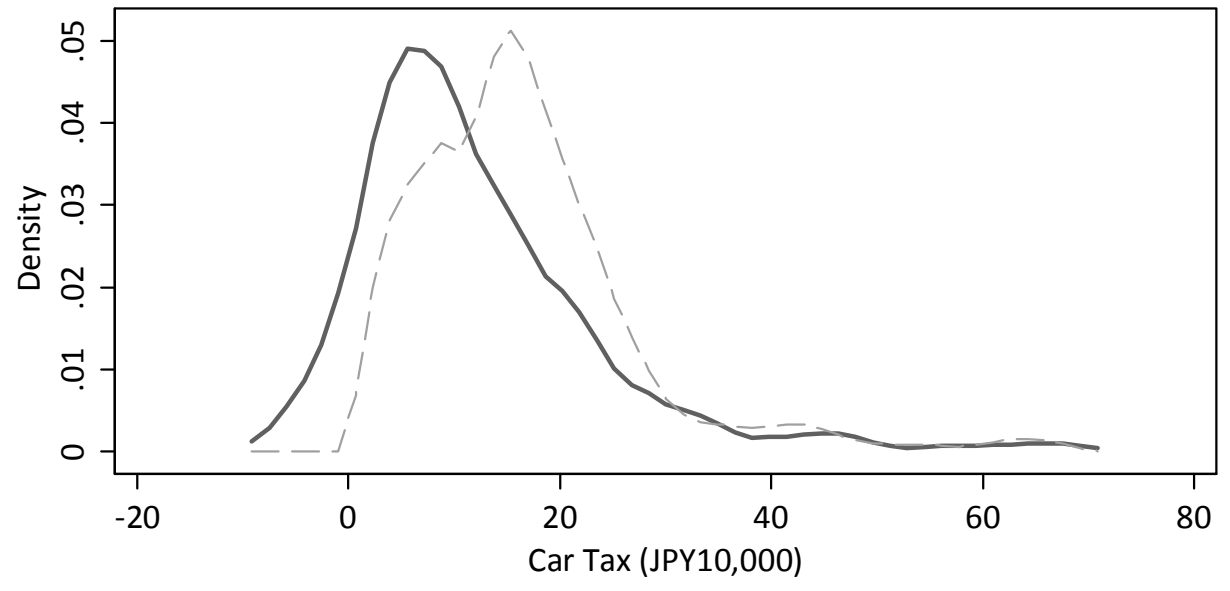

Policy Period $\quad \ldots-\ldots$ Control Period

Note 1: $\mathrm{CO}_{2}$ emissions for each model $=$ Average $\mathrm{CO}_{2}$ emissions per liters of gasoline $/$ mileage per liter of gasoline. Average $\mathrm{CO}_{2}$ emissions per liters of gasoline are taken from EPA (2012). Note 2: Kernel density estimation used the Epanechnikov kernel and the bandwidth of 2.5. 
Figure 2. Trends in Gasoline Price, Car Prices, Car Tax Rates, New Car Sales, and Hybrid Shares
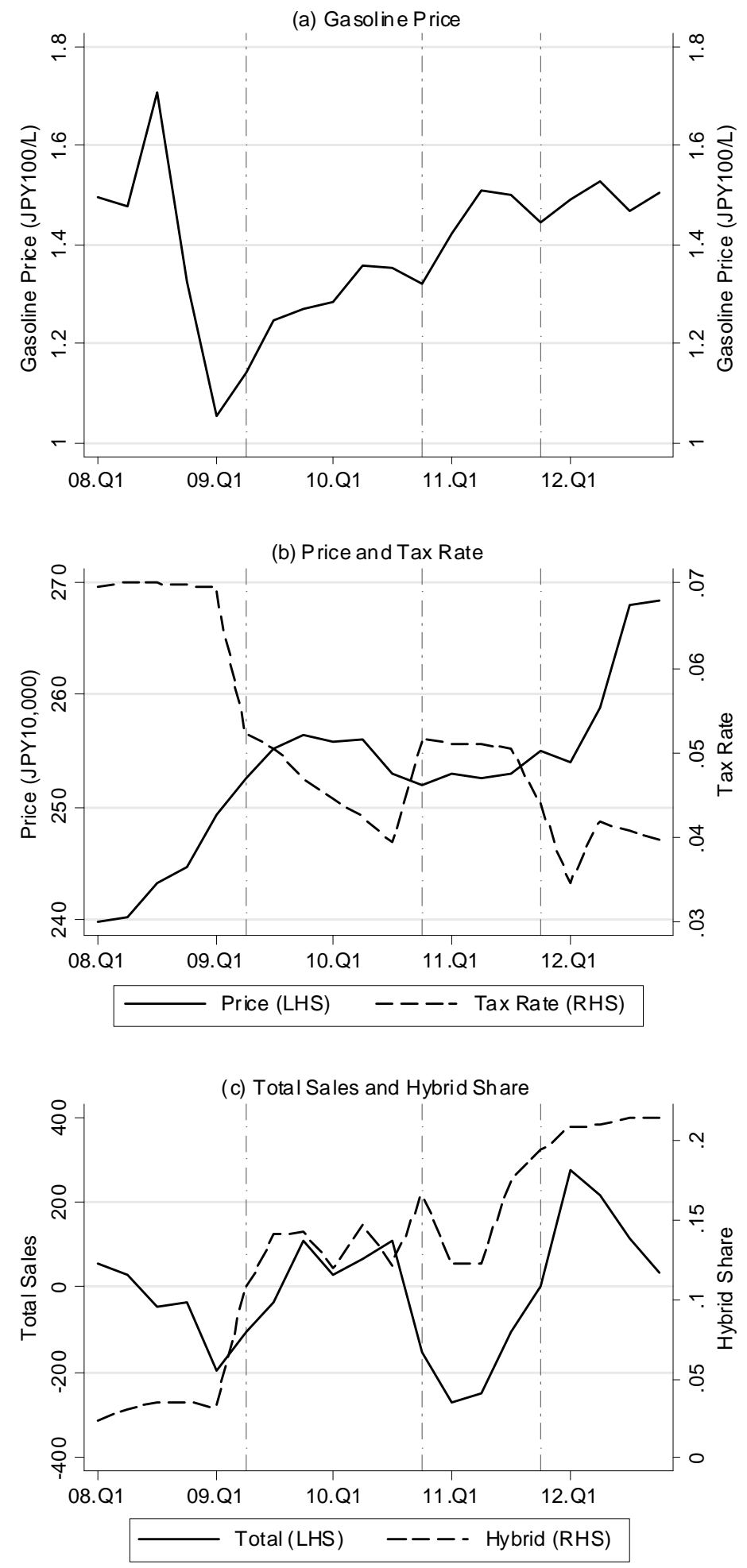
Figure 3. Distribution of Fuel Efficiency in 2007 and 2012

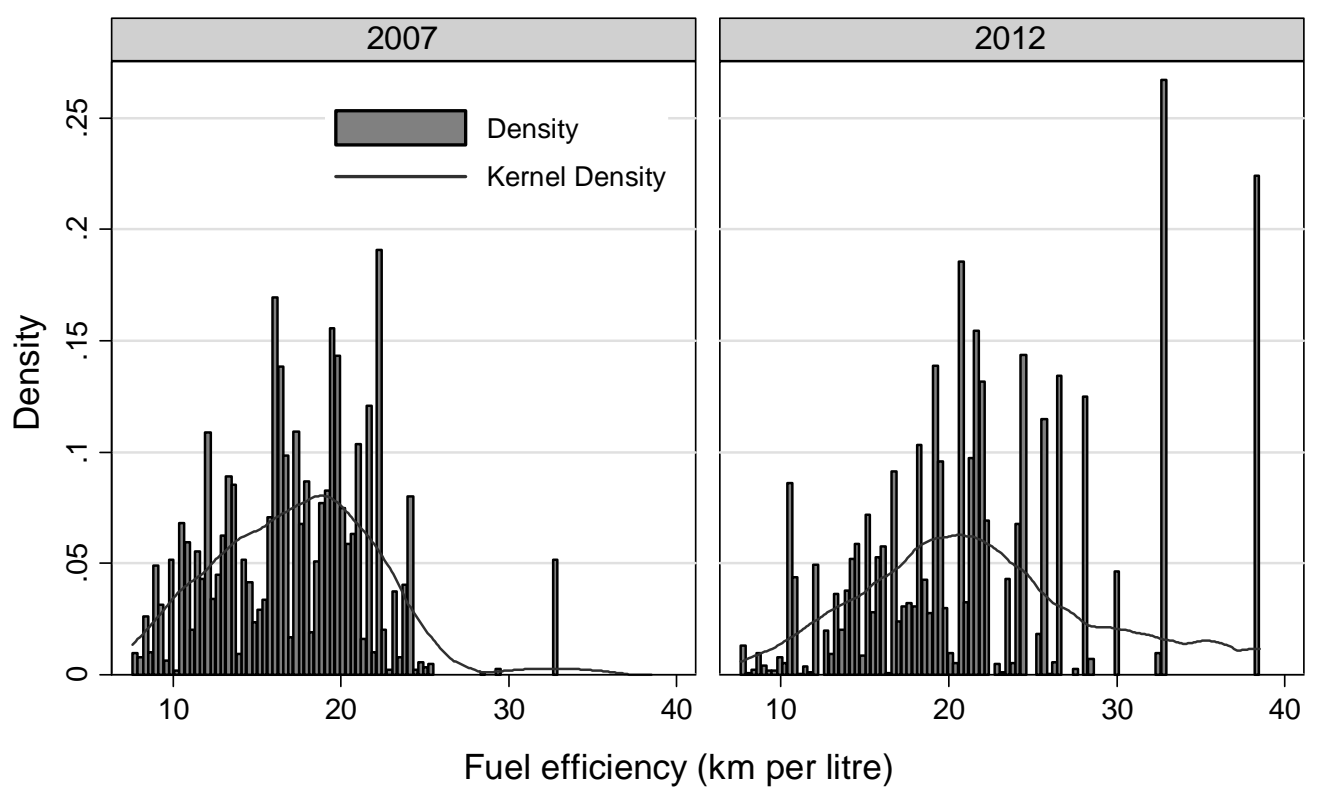


Figure 4. Trends in Monthly New Car Sales from 2008 to 2010

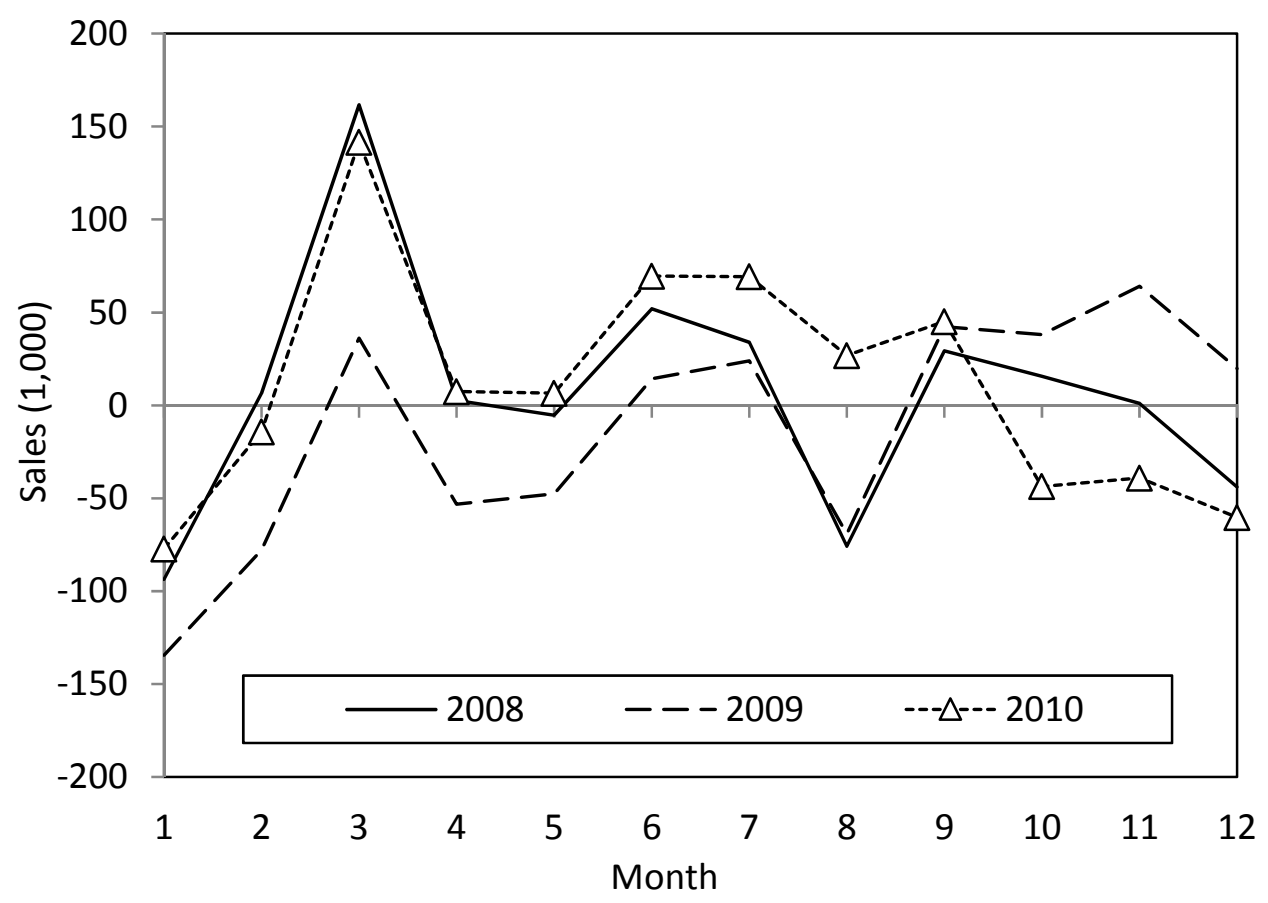


Figure 5. The Estimated Impacts of the ES/ETC Policy on the Average and Distribution of Fuel Efficiency

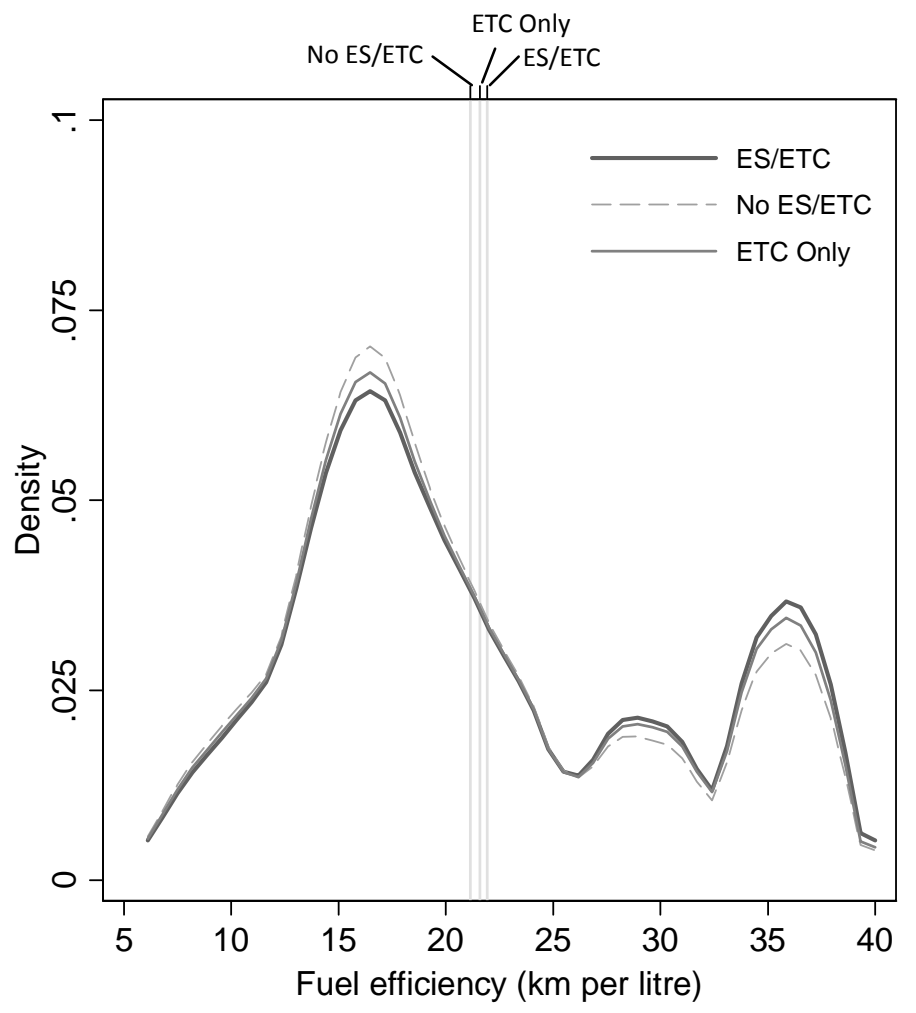

Note: Kernel density estimation used the Epanechnikov kernel and the bandwidth of 1.5. 
Figure 6. The Estimated Impacts of the ES/ETC Policy on the Likelihood of Vehicle Purchase

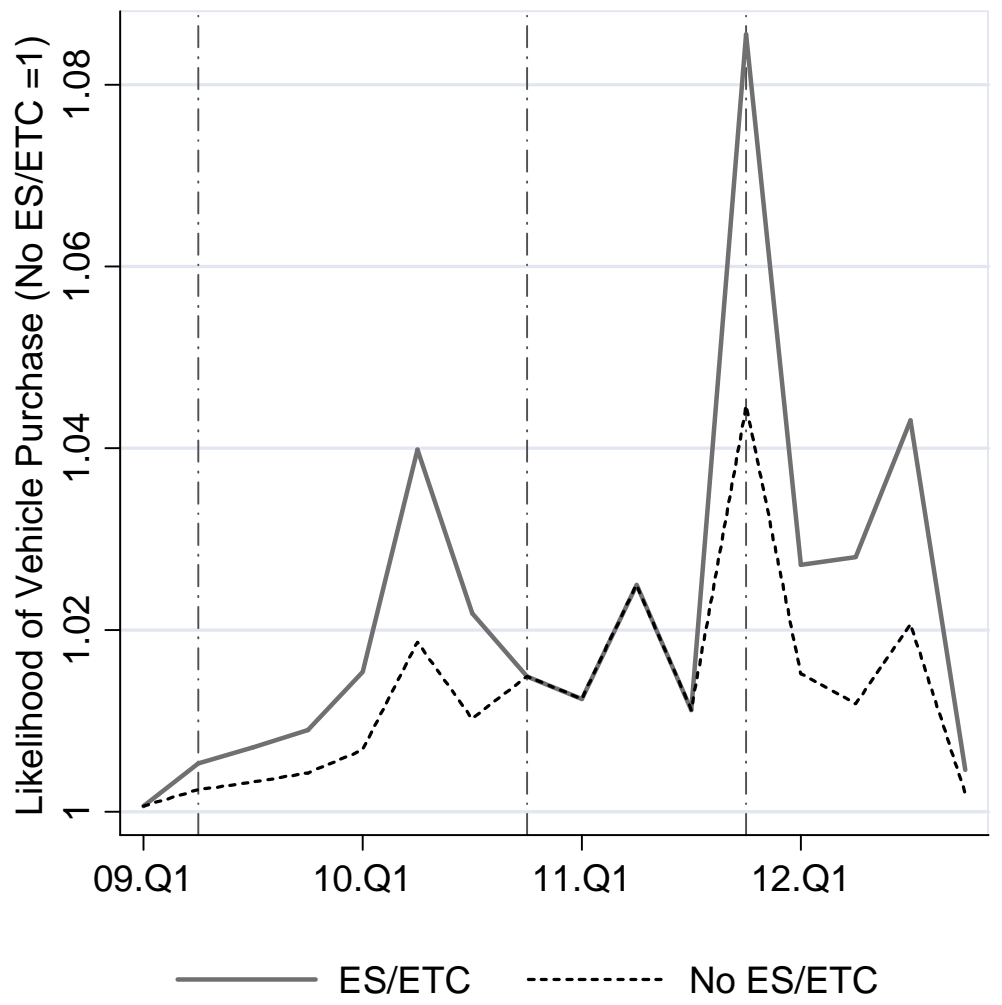


Figure 7. Simulated Impacts of Emissions-based Vehicle Tax

Relative to Pre-existing Equilibrium, Avg. 2009-2012

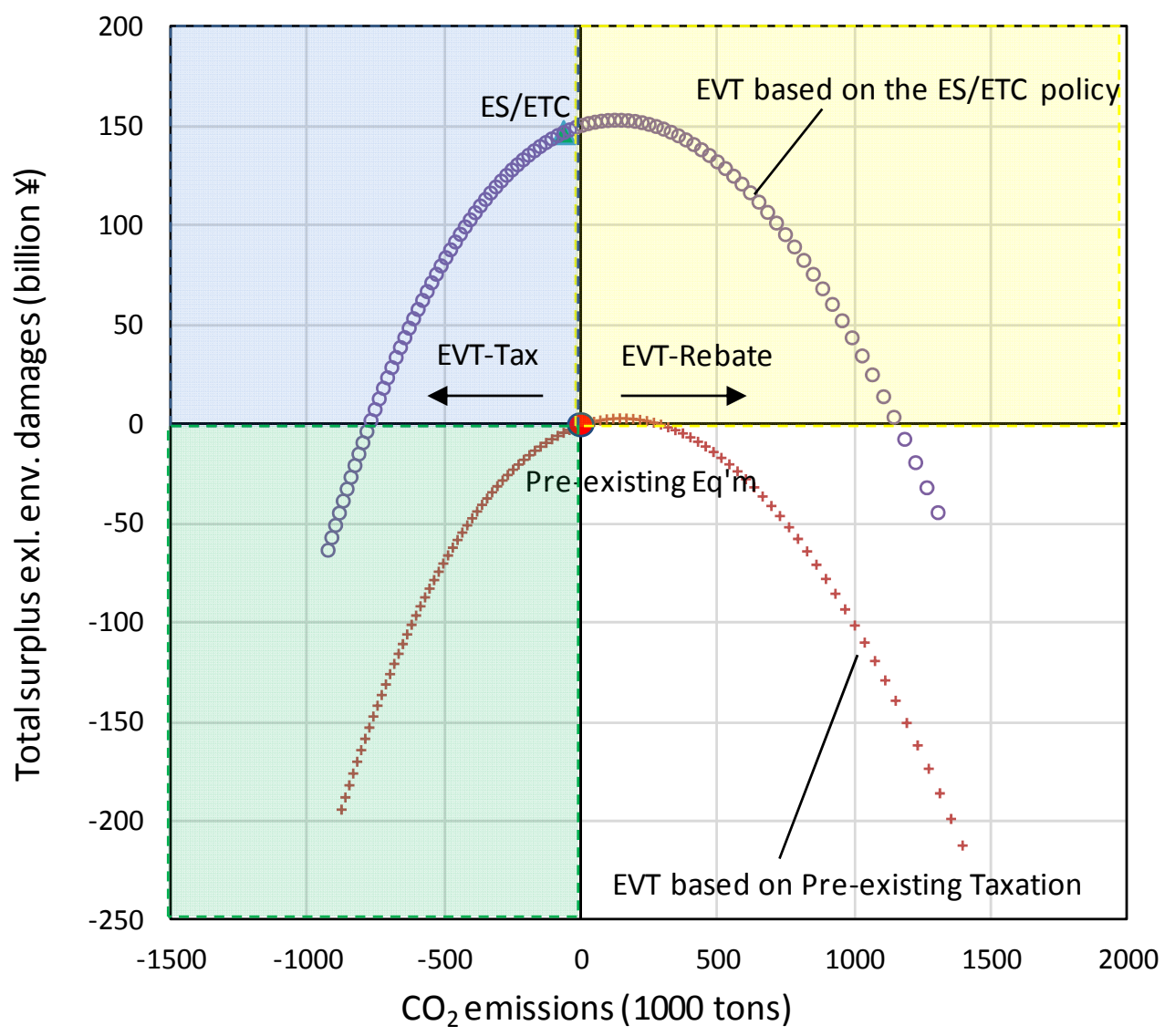


Table 1. Model Eligibility Requirements for ES and ETC

\begin{tabular}{|c|c|c|c|c|c|}
\hline & 2005 Emissions & & 2010 Fuel Eff & ency Standard & \\
\hline & 4 Stars & $115 \%$ or above & Incentives & $125 \%$ or above & Incentives \\
\hline \multicolumn{6}{|l|}{ Passenger Cars } \\
\hline $\mathrm{ES}_{1}$ & $\checkmark$ & $\checkmark$ & JPY 100,000 & $\checkmark$ & JPY 100,000 \\
\hline $\mathrm{ES}_{2}$ & $\checkmark$ & --- & --- & $\checkmark$ & JPY 100,000 \\
\hline ETC (Vehicle Weight Tax) & $\checkmark$ & $\checkmark$ & $50 \%$ tax cut & $\checkmark$ & $75 \%$ tax cut \\
\hline ETC (Acquisition Tax) & $\checkmark$ & $\checkmark$ & $50 \%$ tax cut & $\checkmark$ & $75 \%$ tax cut \\
\hline ETC (Auto Tax) & $\checkmark$ & $\checkmark$ & $25 \%$ tax cut & $\checkmark$ & $50 \%$ tax cut \\
\hline \multicolumn{6}{|l|}{ Minicars } \\
\hline $\mathrm{ES}_{1}$ & $\checkmark$ & $\checkmark$ & JPY 50,000 & $\checkmark$ & JPY 50,000 \\
\hline $\mathrm{ES}_{2}$ & $\checkmark$ & --- & --- & $\checkmark$ & JPY70,000 \\
\hline ETC (Vehicle Weight Tax) & $\checkmark$ & $\checkmark$ & $50 \%$ tax cut & $\checkmark$ & $75 \%$ tax cut \\
\hline ETC (Acquisition Tax) & $\checkmark$ & $\checkmark$ & $50 \%$ tax cut & $\checkmark$ & $75 \%$ tax cut \\
\hline ETC (Auto Tax) & --- & --- & --- & --- & --- \\
\hline
\end{tabular}

Note: Under the first ES policy, the subsidy amount would increase to JPY 250,000 for passenger cars and JPY 125,000 for minicars if consumers replace their owned cars aged 13 years or above. $\mathrm{ES}_{1}$ and $\mathrm{ES}_{2}$ stand for the first and the second phases of the ES program, respectively. The eligibility requirements for tax credits vary over the study period. The requirements in this table refer to those in 2009. 
Table 2. Sales, Price and Product Characteristics of All Brands over Time

\begin{tabular}{|c|c|c|c|c|c|c|c|c|c|c|c|c|}
\hline \multirow[t]{2}{*}{ Quarter } & \multirow[t]{2}{*}{ Models } & \multirow[t]{2}{*}{ Sales } & \multicolumn{2}{|c|}{ Price } & \multicolumn{2}{|c|}{ HP/Weight } & \multicolumn{2}{|c|}{ MPY } & \multicolumn{2}{|c|}{ Size } & \multicolumn{2}{|c|}{$\mathrm{AT} / \mathrm{CVT}$} \\
\hline & & & Mean & S.D. & Mean & S.D. & Mean & S.D. & Mean & S.D. & Mean & S.D. \\
\hline 2007.1 & 153 & $1,177,911$ & 172 & 72 & 0.089 & 0.023 & 13.4 & 3.6 & 7249 & 727 & 0.930 & 0.141 \\
\hline 2007.2 & 151 & 807,883 & 172 & 81 & 0.088 & 0.023 & 13.3 & 3.5 & 7227 & 732 & 0.932 & 0.141 \\
\hline 2007.3 & 145 & 864,876 & 175 & 85 & 0.089 & 0.022 & 12.3 & 3.2 & 7272 & 727 & 0.932 & 0.137 \\
\hline 2007.4 & 147 & 811,305 & 178 & 83 & 0.089 & 0.024 & 11.8 & 3.2 & 7281 & 738 & 0.937 & 0.134 \\
\hline 2008.1 & 149 & $1,134,377$ & 176 & 84 & 0.088 & 0.025 & 11.6 & 3.0 & 7251 & 727 & 0.930 & 0.139 \\
\hline 2008.2 & 152 & 799,539 & 177 & 89 & 0.087 & 0.024 & 12.0 & 3.2 & 7235 & 746 & 0.933 & 0.138 \\
\hline 2008.3 & 153 & 862,397 & 178 & 84 & 0.088 & 0.023 & 10.2 & 2.7 & 7286 & 736 & 0.932 & 0.138 \\
\hline 2008.4 & 155 & 729,635 & 175 & 84 & 0.086 & 0.023 & 13.8 & 3.6 & 7219 & 711 & 0.937 & 0.138 \\
\hline 2009.1 & 156 & 883,547 & 16 & 73 & 0.085 & 0.022 & 17.3 & 4. & 7168 & 663 & 0.933 & 0.139 \\
\hline 2009.2 & 158 & 663,686 & 176 & 80 & 0.085 & 0.022 & 16.8 & 5.1 & 7236 & 655 & 0.938 & 0.135 \\
\hline 2009.3 & 156 & 872,018 & 179 & 76 & 0.086 & 0.021 & 15.7 & 5.4 & 7314 & 637 & 0.939 & 0.121 \\
\hline 2009.4 & 155 & 878,585 & 185 & 83 & 0.086 & 0.021 & 15.3 & 5.2 & 7337 & 657 & 0.939 & 0.115 \\
\hline 2010.1 & 156 & $1,110,119$ & 185 & 89 & 0.087 & 0.022 & 14.8 & 4.9 & 7318 & 666 & 0.921 & 0.130 \\
\hline 2010.2 & 156 & 833,896 & 181 & 80 & 0.085 & 0.021 & 14.5 & 4.9 & 7293 & 652 & 0.916 & 0.138 \\
\hline 2010.3 & 157 & $1,016,468$ & & 81 & 0.086 & & 14.2 & $4 .^{2}$ & 7332 & 658 & 0.920 & 0.134 \\
\hline 2010.4 & 155 & 613,634 & & 86 & 0.085 & 0.023 & 15.3 & 5.3 & 7298 & 677 & 0.927 & 0.143 \\
\hline 2011.1 & 155 & 807,624 & 178 & 82 & 0.084 & 0.022 & 14.2 & 4.5 & 7236 & 666 & 0.924 & 0.167 \\
\hline 2011.2 & 156 & 518,600 & 175 & 77 & 0.083 & 0.022 & 13.4 & 3.9 & 7219 & 650 & 0.918 & 0.174 \\
\hline 2011.3 & 157 & 801,895 & 182 & 81 & 0.083 & 0.022 & 14.0 & 4.3 & 7291 & 638 & 0.928 & 0.169 \\
\hline 2011.4 & 159 & 768,096 & 187 & 84 & 0.083 & 0.022 & 14.7 & 4.6 & 7305 & 679 & 0.936 & 0.160 \\
\hline 2012.1 & 159 & $1,355,977$ & 195 & 83 & 0.080 & 0.021 & 17.2 & 9.7 & 7332 & 647 & 0.946 & 0.149 \\
\hline 2012.2 & 158 & 987,798 & 190 & 86 & 0.079 & 0.020 & 16.8 & 8.9 & 7262 & 655 & 0.944 & 0.149 \\
\hline 2012.3 & 155 & $1,021,995$ & 193 & 85 & 0.080 & 0.021 & 17.6 & 9.5 & 7299 & 637 & 0.941 & 0.155 \\
\hline 2012.4 & 156 & 800,275 & 192 & 96 & 0.080 & 0.022 & 17.3 & 9.0 & 7279 & 637 & 0.945 & 0.152 \\
\hline
\end{tabular}

Note: A hybrid version of the same car brand is treated as a separate brand, so the sales and other product characteristics exclude those of the hybrid model. Price $=$ average retail price in 10,000 JPY; HP/Weight $=$ $\mathrm{HP} /$ weight in $\mathrm{kw} / \mathrm{kg}$; MPY = mileage in $\mathrm{km}$ per JPY; Size = the sum of length, width and height; AT/CVT = the fraction of the car grades that have automatic or continuously variable transmission. 
Table 3. Sales, Price and Product Characteristics of Hybrid Cars over Time

\begin{tabular}{|c|c|c|c|c|c|c|c|c|c|c|c|c|c|}
\hline \multirow[t]{2}{*}{ Quarter } & \multirow[t]{2}{*}{ Models } & \multicolumn{2}{|c|}{ Sales } & \multicolumn{2}{|c|}{ Price } & \multicolumn{2}{|c|}{ HP/Weight } & \multicolumn{2}{|c|}{ MPY } & \multicolumn{2}{|c|}{ Size } & \multicolumn{2}{|c|}{$\mathrm{AT} / \mathrm{CVT}$} \\
\hline & & Total & Share & Mean & S.D. & Mean & S.D. & Mean & S.D. & Mean & S.D. & Mean & S.D. \\
\hline 2007.1 & 7 & 23,628 & 0.020 & 275 & 85 & 0.067 & 0.016 & 22.5 & 4.8 & 7,852 & 316 & 1 & 0 \\
\hline 2007.2 & 7 & 19,125 & 0.024 & 328 & 230 & 0.073 & 0.031 & 21.5 & 5.5 & 7,864 & 327 & 1 & 0 \\
\hline 2007.3 & 7 & 21,309 & 0.025 & 362 & 279 & 0.077 & 0.037 & 19.7 & 5.5 & 7,880 & 338 & 1 & 0 \\
\hline 2007.4 & 7 & 21,187 & 0.026 & 316 & 223 & 0.071 & 0.030 & 19.8 & 4.7 & 7,825 & 307 & 1 & 0 \\
\hline 2008.1 & 8 & 26,634 & 0.023 & 321 & 223 & 0.072 & 0.031 & 19.0 & 4.7 & 7,843 & 318 & 1 & 0 \\
\hline 2008.2 & 8 & 24,644 & 0.031 & 329 & 210 & 0.078 & 0.037 & 19.2 & 5.0 & 7,839 & 286 & 1 & 0 \\
\hline 2008.3 & 7 & 29,963 & 0.035 & 323 & 173 & 0.079 & 0.036 & 16.2 & 4.2 & 7,856 & 286 & 1 & 0 \\
\hline 2008.4 & 7 & 25,832 & 0.035 & 299 & 160 & 0.071 & 0.029 & 22.5 & 4.8 & 7,802 & 266 & 1 & 0 \\
\hline 2009.1 & 8 & 28,426 & 0.032 & 245 & 99 & 0.068 & 0.018 & 28.6 & 4.1 & 7,676 & 221 & 1 & 0 \\
\hline 2009.2 & 9 & 70,575 & 0.106 & 239 & 101 & 0.074 & 0.016 & 27.2 & 4.4 & 7,680 & 230 & 1 & 0 \\
\hline 2009.3 & 10 & 122,798 & 0.141 & 233 & 86 & 0.074 & 0.013 & 26.2 & 4.2 & 7,704 & 204 & 1 & 0 \\
\hline 2009.4 & 11 & 124,989 & 0.142 & 245 & 103 & 0.075 & 0.014 & 25.2 & 4.4 & 7,715 & 204 & 1 & 0 \\
\hline 2010.1 & 12 & 132,374 & 0.119 & 264 & 130 & 0.079 & 0.018 & 24.5 & 5.1 & 7,742 & 217 & 1 & 0 \\
\hline 2010.2 & 12 & 122,369 & 0.147 & 242 & 92 & 0.077 & 0.015 & 23.8 & 4.3 & 7,689 & 205 & 1 & 0 \\
\hline 2010.3 & 12 & 123,358 & 0.121 & 248 & 107 & 0.077 & 0.017 & 23.8 & 4.5 & 7,703 & 219 & 1 & 0 \\
\hline 2010.4 & 14 & 102,012 & 0.166 & 227 & 99 & 0.076 & 0.016 & 24.6 & 3.8 & 7,580 & 306 & 0.992 & 0.064 \\
\hline 2011.1 & 14 & 98,710 & 0.122 & 235 & 103 & 0.076 & 0.016 & 22.6 & 3.6 & 7,562 & 313 & 0.986 & 0.082 \\
\hline 2011.2 & 14 & 63,359 & 0.122 & 244 & 93 & 0.075 & 0.016 & 20.6 & 2.6 & 7,623 & 298 & 0.986 & 0.082 \\
\hline 2011.3 & 15 & 141,087 & 0.176 & 254 & 96 & 0.073 & 0.015 & 20.6 & 2.4 & 7,748 & 235 & 0.996 & 0.045 \\
\hline 2011.4 & 19 & 148,781 & 0.194 & 254 & 86 & 0.073 & 0.015 & 20.9 & 2.9 & 7,782 & 239 & 0.996 & 0.044 \\
\hline 2012.1 & 19 & 282,623 & 0.208 & 231 & 81 & 0.071 & 0.012 & 21.3 & 3.5 & 7,636 & 371 & 0.996 & 0.043 \\
\hline 2012.2 & 21 & 207,197 & 0.210 & 233 & 99 & 0.073 & 0.014 & 20.9 & 3.8 & 7,594 & 406 & 0.987 & 0.043 \\
\hline 2012.3 & 24 & 219,347 & 0.215 & 234 & 98 & 0.074 & 0.015 & 21.6 & 4.4 & 7,619 & 424 & 0.947 & 0.195 \\
\hline 2012.4 & 24 & 171,833 & 0.215 & 229 & 120 & 0.073 & 0.015 & 21.7 & 4.4 & 7,557 & 430 & 0.949 & 0.196 \\
\hline
\end{tabular}

Note Price $=$ average retail price in 10,000 JPY; HP/Weight $=\mathrm{HP} /$ weight in $\mathrm{kw} / \mathrm{kg}$; MPY $=$ mileage in $\mathrm{km}$ per JPY; Size = the sum of length, width and height; AT/CVT $=$ the fraction of the car grades that have automatic or continuously variable transmission. 
Table 4. Sales, Price and Product Characteristics of Minicars over Time

\begin{tabular}{|c|c|c|c|c|c|c|c|c|c|c|c|c|c|}
\hline \multirow[t]{2}{*}{ Quarter } & \multirow[t]{2}{*}{ Models } & \multicolumn{2}{|c|}{ Sales } & \multicolumn{2}{|c|}{ Price } & \multicolumn{2}{|c|}{ HP/Weight } & \multicolumn{2}{|c|}{ MPY } & \multicolumn{2}{|c|}{ Size } & \multicolumn{2}{|c|}{$\mathrm{AT} / \mathrm{CVT}$} \\
\hline & & Total & Share & Mean & S.D. & Mean & S.D. & Mean & S.D. & Mean & S.D. & Mean & S.D. \\
\hline 2007.1 & 34 & 393,824 & 0.334 & 116 & 12 & 0.066 & 0.005 & 16.5 & 1.5 & 6,456 & 412 & 0.925 & 0.168 \\
\hline 2007.2 & 35 & 279,763 & 0.346 & 116 & 12 & 0.066 & 0.005 & 16.1 & 1.5 & 6,456 & 446 & 0.935 & 0.167 \\
\hline 2007.3 & 34 & 268,102 & 0.310 & 117 & 12 & 0.066 & 0.005 & 15.0 & 1.5 & 6,455 & 472 & 0.948 & 0.165 \\
\hline 2007.4 & 34 & 249,394 & 0.307 & 117 & 12 & 0.066 & 0.005 & 14.5 & 1.4 & 6,451 & 516 & 0.946 & 0.166 \\
\hline 2008.1 & 35 & 376,292 & 0.332 & 118 & 12 & 0.065 & 0.005 & 14.1 & 1.3 & 6,470 & 464 & 0.948 & 0.170 \\
\hline 2008.2 & 35 & 278,631 & 0.3 & 118 & 12 & 0.065 & 0.005 & 14.4 & 1.4 & 6,474 & 500 & 0.950 & 0.167 \\
\hline 2008.3 & 36 & 266,074 & 0.309 & 118 & 12 & 0.065 & 0.005 & 12.4 & 1.2 & 6,473 & 490 & 0.947 & 0.172 \\
\hline 2008.4 & 36 & 267,351 & 0.366 & 119 & 12 & 0.065 & 0.005 & 16.3 & 1.6 & 6,490 & 295 & 0.946 & 0.172 \\
\hline 2009.1 & 35 & 337,038 & 0.381 & 119 & 12 & 0.065 & 0.005 & 20.3 & 2.2 & 6,506 & 96 & 0.946 & 0.168 \\
\hline 2009.2 & 35 & 221,059 & 0.333 & 119 & 11 & 0.065 & 0.004 & 18.7 & 2.0 & 6,512 & 97 & 0.950 & 0.168 \\
\hline 2009.3 & 33 & 231,049 & 0.265 & 119 & 11 & 0.065 & 0.004 & 17.1 & 1.9 & 6,508 & 94 & 0.954 & 0.151 \\
\hline 2009.4 & 34 & 239,032 & 0.272 & 119 & 11 & 0.065 & 0.005 & 16.5 & 1.9 & 6,511 & 93 & 0.938 & 0.139 \\
\hline 2010.1 & 34 & 330,702 & 0.298 & 119 & 12 & 0.064 & 0.005 & 16.3 & 1.6 & 6,518 & 93 & 0.901 & 0.155 \\
\hline 2010.2 & 34 & 255,808 & 0.307 & 119 & 13 & 0.065 & 0.005 & 15.2 & 1.6 & 6,518 & 97 & 0.894 & 0.162 \\
\hline 2010.3 & 34 & 289,906 & 0.285 & 120 & 12 & 0.065 & 0.005 & 15.3 & 1.7 & 6,518 & 94 & 0.897 & 0.159 \\
\hline 2010.4 & 33 & 198,791 & 0.324 & 121 & 13 & 0.064 & 0.005 & 15.9 & 2.1 & 6,523 & 97 & 0.902 & 0.172 \\
\hline 2011.1 & 33 & 282,195 & 0.349 & 121 & 12 & 0.064 & 0.005 & 15.2 & 2.3 & 6,515 & 89 & 0.930 & 0.159 \\
\hline 2011.2 & 33 & 186,504 & 0.360 & 121 & 11 & 0.064 & 0.005 & 14.5 & 2.2 & 6,516 & 90 & 0.924 & 0.166 \\
\hline 2011.3 & 33 & 248,801 & 0.310 & 121 & 12 & 0.062 & 0.006 & 14.9 & 2.5 & 6,519 & 94 & 0.941 & 0.162 \\
\hline 2011.4 & 33 & 252,487 & 0.329 & 119 & 13 & 0.063 & 0.005 & 15.9 & 2.8 & 6,502 & 96 & 0.945 & 0.157 \\
\hline 2012.1 & 32 & 398,727 & & 122 & 14 & & 0.005 & 15.2 & 2.4 & 6,520 & 100 & 0.949 & 0.147 \\
\hline 2012.2 & 32 & 344,514 & 0.349 & 124 & 14 & 0.062 & 0.005 & 14.7 & 2.1 & 6,531 & 103 & 0.952 & 0.142 \\
\hline 2012.3 & 29 & 319,920 & 0.313 & 125 & 14 & 0.062 & 0.005 & 15.3 & 2.1 & 6,534 & 105 & 0.964 & 0.122 \\
\hline 2012.4 & 30 & 259,827 & 0.325 & 125 & 13 & 0.063 & 0.005 & 15.2 & 2.1 & 6,532 & 102 & 0.962 & 0.138 \\
\hline
\end{tabular}

Note: Price $=$ average retail price in 10,000 JPY; HP/Weight $=\mathrm{HP} /$ weight in $\mathrm{kw} / \mathrm{kg} ; \mathrm{MPY}=$ mileage in $\mathrm{km}$ per JPY; Size = the sum of length, width and height; $\mathrm{AT} / \mathrm{CVT}=$ the fraction of the car grades that have automatic or continuously variable transmission. 


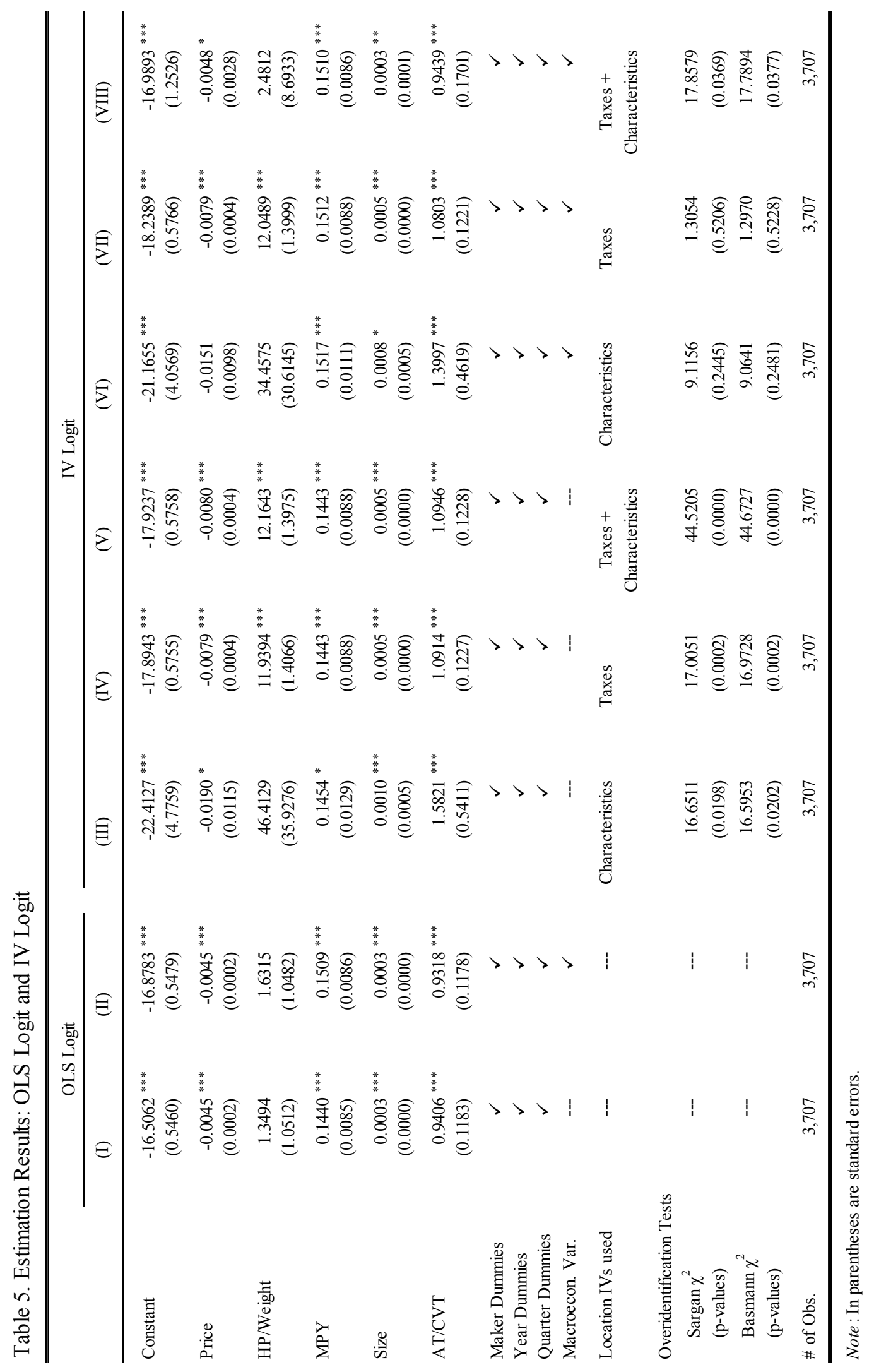


Table 6. Estimation Results: Full Random-Coefficients Logit

\begin{tabular}{|c|c|c|c|c|c|}
\hline & \multirow{2}{*}{$\begin{array}{l}\text { IV Logit } \\
\text { (VII) }\end{array}$} & \multicolumn{2}{|c|}{$\begin{array}{l}\text { RC Logit } \\
\text { (IX) }\end{array}$} & \multicolumn{2}{|c|}{$\begin{array}{l}\text { RC Logit } \\
\text { (X) }\end{array}$} \\
\hline & & Mean & St. Dev. & Mean & St. Dev. \\
\hline Constant & $\begin{array}{l}-18.2389^{* * *} \\
(0.5766)\end{array}$ & $\begin{array}{l}-30.5160^{* * *} \\
(7.7979)\end{array}$ & $\begin{array}{l}9.4262^{* * *} \\
(3.0104)\end{array}$ & $\begin{array}{l}-37.9420^{* * *} \\
(1.7219)\end{array}$ & $\begin{array}{l}11.9260 \text { *** } \\
(0.6209)\end{array}$ \\
\hline Price & $\begin{array}{l}-0.0079^{* * *} \\
(0.0004)\end{array}$ & $\begin{array}{l}-0.0302^{* *} \\
(0.0183)\end{array}$ & $\begin{array}{r}0.0051 \\
(0.0046)\end{array}$ & $\begin{array}{l}-0.0292^{* * *} \\
(0.0011)\end{array}$ & $\begin{array}{l}0.0119^{* * *} \\
(0.0035)\end{array}$ \\
\hline HP/Weight & $\begin{array}{l}12.0489^{* * * *} \\
(1.3999)\end{array}$ & $\begin{array}{r}61.0120 \\
(57.0430)\end{array}$ & $\begin{array}{r}9.6523 \\
(25.9820)\end{array}$ & $\begin{array}{l}22.6240 \text { *** } \\
(3.5820)\end{array}$ & $\begin{array}{l}11.4320^{* * *} \\
(0.8363)\end{array}$ \\
\hline MPY & $\begin{array}{l}0.1512^{* * * *} \\
(0.0088)\end{array}$ & $\begin{array}{l}0.1422^{* * *} \\
(0.0195)\end{array}$ & $\begin{array}{r}0.1433 \\
(0.1588)\end{array}$ & $\begin{array}{l}0.2622^{* * *} \\
(0.0214)\end{array}$ & $\begin{array}{l}0.13644^{* *} \\
(0.0589)\end{array}$ \\
\hline Size & $\begin{array}{l}0.0005^{* * *} \\
(0.0000)\end{array}$ & $\begin{array}{l}0.0014^{* *} \\
(0.0009)\end{array}$ & $\begin{array}{r}0.0005 \\
(0.0008)\end{array}$ & $\begin{array}{l}0.0015^{* * *} \\
(0.0001)\end{array}$ & $\begin{array}{l}0.0013^{* * *} \\
(0.0003)\end{array}$ \\
\hline $\mathrm{AT} / \mathrm{CVT}$ & $\begin{array}{l}1.0803^{* * *} \\
(0.1221)\end{array}$ & $\begin{array}{l}1.8009^{* *} \\
(0.8423)\end{array}$ & $\begin{array}{r}0.9699 \\
(2.1944)\end{array}$ & $\begin{array}{l}1.1133^{* * *} \\
(0.2144)\end{array}$ & $\begin{array}{c}1.4209^{*} \\
(0.9214)\end{array}$ \\
\hline Maker Dummies & $\checkmark$ & & & & \\
\hline Year Dummies & $\checkmark$ & & & & \\
\hline Quarter Dummies & $\checkmark$ & & & & \\
\hline Macroecon. Var. & $\checkmark$ & & & & \\
\hline Location IVs used & Taxes & Chara & stics & & \\
\hline \# of Obs. & 3,707 & & & & \\
\hline GMM Obj. & --- & & & & \\
\hline
\end{tabular}

Note: In parentheses are standard errors. Inner-loop tolerance for NFP =1E-14. Outer-loop tolerance for GMM = $1 \mathrm{E}-3$. 
Table 7. Product Characteristics, Estimated Elasticities, and Implied Price-cost Margins of the Top 15 Sales Brands for 2011

\begin{tabular}{lrrrrrrrrr}
\hline \multicolumn{1}{c}{ Brand Name } & Sales & Price & HP/Weight & MPY & Size & AT/CVT & $\begin{array}{c}\text { Own-price } \\
\text { elasticities }\end{array}$ & $\begin{array}{c}\text { Price-cost } \\
\text { Margin }\end{array}$ & $\begin{array}{c}\text { Outside } \\
\text { Substitution }\end{array}$ \\
\hline Toyota Prius & 252,232 & 236 & 0.069 & 23.1 & 7,807 & 1.000 & -6.535 & 0.28 & 10.23 \\
Daihatsu Move & 145,201 & 128 & 0.063 & 18.1 & 6,502 & 1.000 & -0.902 & 0.25 & 15.03 \\
Daihatsu Tanto & 129,118 & 126 & 0.057 & 16.5 & 6,620 & 1.000 & -0.717 & 0.25 & 13.12 \\
Toyota Vitz & 128,725 & 135 & 0.092 & 15.1 & 7,094 & 0.938 & -3.096 & 0.39 & 9.52 \\
Daihatsu Mira & 120,014 & 108 & 0.069 & 17.8 & 6,405 & 0.905 & -1.843 & 0.29 & 15.89 \\
Honda Fit & 105,310 & 140 & 0.098 & 13.3 & 7,208 & 0.786 & -2.255 & 0.24 & 8.54 \\
Honda Fit Hybrid & 102,386 & 173 & 0.076 & 20.4 & 7,295 & 1.000 & -7.666 & 0.22 & 11.25 \\
Suzuki Alto & 83,100 & 102 & 0.070 & 14.7 & 6,400 & 0.714 & -0.673 & 0.29 & 14.98 \\
Honda Life & 67,574 & 114 & 0.059 & 12.4 & 6,500 & 1.000 & -0.748 & 0.28 & 13.21 \\
Mazda Demio & 61,902 & 127 & 0.098 & 14.1 & 7,065 & 0.681 & -2.520 & 0.23 & 9.32 \\
Nissan Moco & 61,766 & 117 & 0.068 & 14.8 & 6,495 & 1.000 & -1.523 & 0.28 & 13.59 \\
Toyota Ractis & 58,964 & 152 & 0.090 & 13.2 & 7,282 & 1.000 & -4.334 & 0.36 & 8.00 \\
Honda Freed & 56,345 & 184 & 0.087 & 10.7 & 7,635 & 1.000 & -2.231 & 0.20 & 6.31 \\
Suzuki Palette & 54,825 & 127 & 0.059 & 13.0 & 6,610 & 1.000 & -0.505 & 0.24 & 12.22 \\
Toyota Passo & 53,973 & 117 & 0.079 & 14.4 & 6,844 & 1.000 & -4.388 & 0.42 & 10.68 \\
\hline \hline
\end{tabular}

Note: A hybrid version of the same car brand is treated as a separate brand, so the sales and other product characteristics exclude those of the hybrid model. Price = average retail price in 10,000 JPY; HP/Weight = $\mathrm{HP} /$ weight in $\mathrm{kw} / \mathrm{kg}$; MPY = mileage in $\mathrm{km}$ per JPY; Size = the sum of length, width and height; AT/CVT = the fraction of the car grades that have automatic (AT) or continuously variable (CVT) transmission; Outside substitution $=$ estimated percentage of consumers who substitute to the outside good as a percentage of those who substitute away from the good, given a price increase of the good. All quantities are simple averages, except for sales, which is the sum of sales for 2011. 


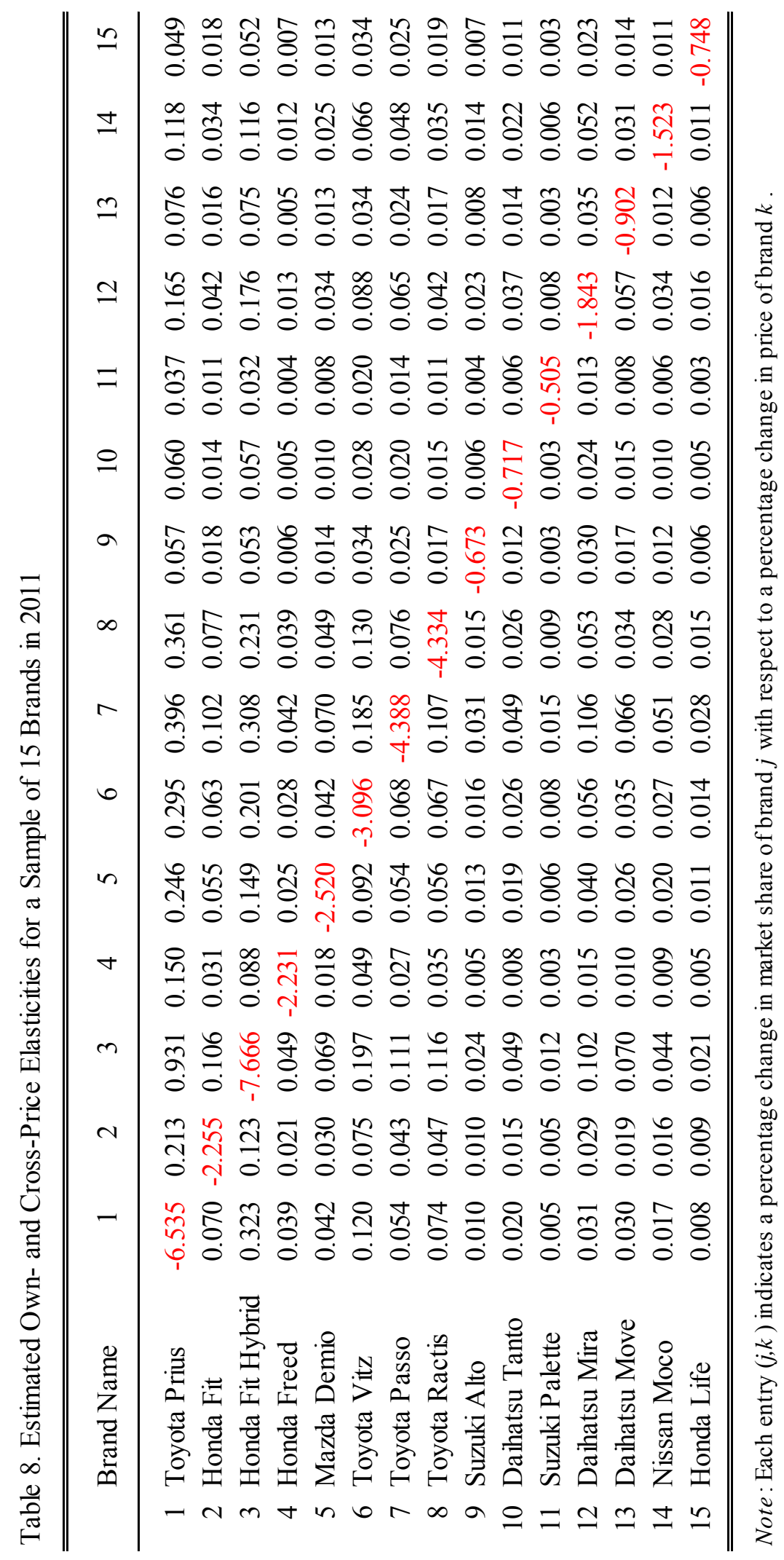


Table 9. Decomposition of the Simulated Impacts on Expected Aggregate Emissions from the New Car Sales

\begin{tabular}{|c|c|c|c|c|c|c|c|c|}
\hline & $\begin{array}{c}\text { No Policy } \\
\text { (1) }\end{array}$ & $\begin{array}{c}\text { ETC Only } \\
\text { (2) }\end{array}$ & $\begin{array}{c}\text { ES/ETC } \\
(3)\end{array}$ & & $\begin{array}{c}\text { Diff. } \\
(2)-(1)\end{array}$ & $\begin{array}{c}\text { S.E. } \\
\text { of Diff. }\end{array}$ & $\begin{array}{l}\text { Diff. } \\
(3)-(1)\end{array}$ & $\begin{array}{l}\text { S.E. } \\
\text { of Diff. }\end{array}$ \\
\hline 2009 & 4,311 & 4,248 & 4,198 & $\begin{array}{l}\text { Total Effect: } \\
\text { Scale } \\
\text { Compotition }\end{array}$ & $\begin{array}{r}-63.5 \\
11.3 \\
-74.8\end{array}$ & $(41.4)$ & $\begin{array}{r}-112.6 \\
22.9 \\
-135.5\end{array}$ & (23.4) \\
\hline 2010 & 4,749 & 4,719 & 4,704 & $\begin{array}{l}\text { Total Effect: } \\
\text { Scale } \\
\text { Compotition }\end{array}$ & $\begin{array}{r}-30.6 \\
58.2 \\
-88.8\end{array}$ & $(64.0)$ & $\begin{array}{r}-45.4 \\
106.5 \\
-151.9\end{array}$ & (53.5) \\
\hline 2011 & 3,665 & 3,658 & 3,657 & $\begin{array}{l}\text { Total Effect: } \\
\text { Scale } \\
\text { Compotition }\end{array}$ & $\begin{array}{r}-6.4 \\
74.7 \\
-81.1\end{array}$ & (147.7) & $\begin{array}{r}-7.5 \\
102.3 \\
-109.8\end{array}$ & (83.8) \\
\hline 2012 & 3,854 & 3,800 & 3,757 & $\begin{array}{l}\text { Total Effect: } \\
\text { Scale } \\
\text { Compotition }\end{array}$ & $\begin{array}{r}-54.0 \\
44.4 \\
-98.4\end{array}$ & $(49.2)$ & $\begin{array}{r}-97.0 \\
88.2 \\
-185.2\end{array}$ & (31.7) \\
\hline Annual & 4,145 & 4,106 & 4,079 & $\begin{array}{l}\text { Total Effect: } \\
\text { Scale } \\
\text { Compotition }\end{array}$ & $\begin{array}{r}-38.6 \\
47.1 \\
-85.8\end{array}$ & $(45.0)$ & $\begin{array}{r}-65.6 \\
80.0 \\
-145.6\end{array}$ & (29.8) \\
\hline
\end{tabular}

Note: All numbers are in 1000 tons of carbon dioxides emissions. In parentheses are standard errors. 
Table 10. Simulated Impacts of the ETC/ES Policy on Aggregate Emissions, Compensating Variation, Industry Profits, and Tax Revenues

\begin{tabular}{|c|c|c|c|c|c|c|c|c|}
\hline & \multicolumn{6}{|c|}{ Changes relative to the no-policy countefactual } & \multirow{2}{*}{\multicolumn{2}{|c|}{ Tax revenues }} \\
\hline & \multicolumn{2}{|c|}{ Vehicle emissions } & \multicolumn{2}{|c|}{ Compensating variation } & \multicolumn{2}{|c|}{ Industry profits } & & \\
\hline & \multicolumn{2}{|c|}{$\begin{array}{l}\text { ES/ETC ETC Only } \\
\left(1000 \text { tons of } \mathrm{CO}_{2}\right)\end{array}$} & \multicolumn{2}{|c|}{$\begin{array}{c}\text { ES/ETC ETC Only } \\
\text { (billion } ¥)\end{array}$} & \multicolumn{2}{|c|}{$\begin{array}{c}\text { ES/ETC ETC Only } \\
\text { (billion } ¥)\end{array}$} & \multicolumn{2}{|c|}{$\begin{array}{c}\text { ES/ETC ETC Only } \\
\text { (billion } ¥)\end{array}$} \\
\hline 2009 & $\begin{array}{r}-112.61 \\
(41.4)\end{array}$ & $\begin{array}{l}-63.48 \\
(23.4)\end{array}$ & $\begin{array}{r}289.03 \\
(36.5)\end{array}$ & $\begin{array}{r}148.07 \\
(23.7)\end{array}$ & $\begin{array}{r}90.20 \\
(16.9)\end{array}$ & $\begin{array}{c}51.48 \\
(12.9)\end{array}$ & $\begin{array}{r}-307.67 \\
(35.5)\end{array}$ & $\begin{array}{r}-153.59 \\
(22.7)\end{array}$ \\
\hline 2010 & $\begin{array}{c}-45.45 \\
(64.0)\end{array}$ & $\begin{array}{c}-30.61 \\
(53.5)\end{array}$ & $\begin{array}{r}364.61 \\
(43.1)\end{array}$ & $\begin{array}{r}203.72 \\
(30.7)\end{array}$ & $\begin{array}{r}112.71 \\
(46.2)\end{array}$ & $\begin{array}{c}65.08 \\
(34.2)\end{array}$ & $\begin{array}{r}-388.08 \\
(43.8)\end{array}$ & $\begin{array}{r}-210.32 \\
(28.7)\end{array}$ \\
\hline 2011 & $\begin{array}{r}-7.46 \\
(147.7)\end{array}$ & $\begin{array}{r}-6.37 \\
(83.8)\end{array}$ & $\begin{array}{r}170.27 \\
(21.8)\end{array}$ & $\begin{array}{r}152.18 \\
(17.8)\end{array}$ & $\begin{array}{r}69.39 \\
(146.4)\end{array}$ & $\begin{array}{r}46.93 \\
(68.5)\end{array}$ & $\begin{array}{r}-193.90 \\
(96.7)\end{array}$ & $\begin{array}{r}-165.11 \\
(47.6)\end{array}$ \\
\hline 2012 & $\begin{array}{c}-97.01 \\
(49.2)\end{array}$ & $\begin{array}{c}-54.01 \\
(31.7)\end{array}$ & $\begin{array}{r}671.61 \\
(59.9)\end{array}$ & $\begin{array}{r}225.11 \\
(34.3)\end{array}$ & $\begin{array}{r}410.45 \\
(93.4)\end{array}$ & $\begin{array}{c}-28.19 \\
(57.0)\end{array}$ & $\begin{array}{r}-698.68 \\
(59.3)\end{array}$ & $\begin{array}{r}-229.04 \\
(34.1)\end{array}$ \\
\hline Avg. & $\begin{array}{c}-65.63 \\
(45.0)\end{array}$ & $\begin{array}{c}-38.62 \\
(29.8)\end{array}$ & $\begin{array}{r}373.88 \\
(36.7)\end{array}$ & $\begin{array}{r}182.27 \\
(23.9)\end{array}$ & $\begin{array}{r}170.69 \\
(48.1)\end{array}$ & $\begin{array}{c}33.82 \\
(28.5)\end{array}$ & $\begin{array}{r}-397.08 \\
(48.1)\end{array}$ & $\begin{array}{r}-189.51 \\
(27.2)\end{array}$ \\
\hline
\end{tabular}

Note: In parentheses are standard errors. 
Online Appendix: Lowess Regression of Monthly Driving Distance on Fuel Efficiency A Cross-sectional Sample of 1,371 Drivers in Japan

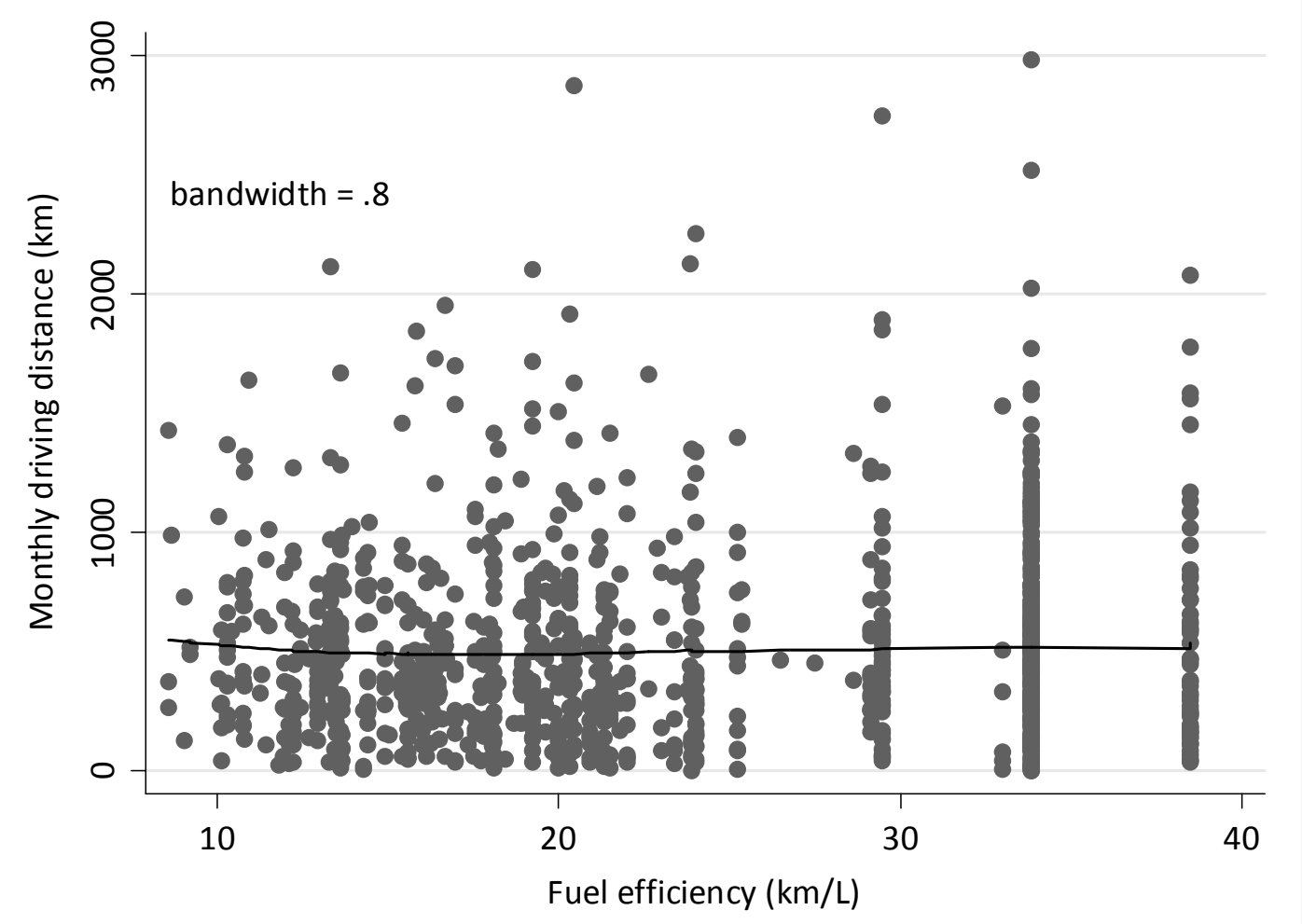

Note: We thank Shigeru Matsumoto at Aoyama Gakuin University for kindly sharing the data for our use. We do not make explicit use of the data for our analysis, since the survey only includes the information on car owners and is only a cross-sectional sample collected in 2013, which is outside our study period. 